\title{
Evaluating the adaptive potential of the European eel: is the immunogenetic status recovering?
}

Miguel Baltazar-Soares, Seraina E. Bracamonte, Till Bayer, Frédéric J.J. Chain, Reinhold Hanel, Chris Harrod, Christophe Eizaguirre The recent increased integration of evolutionary theory into conservation programs has greatly improved our ability to protect endangered species. A common application of such theory links population dynamics and indices of genetic diversity, usually estimated from neutrally evolving markers. Some studies however have suggested that highly polymorphic adaptive genes, such as the immune genes of the Major Histocompatibility Complex (MHC), might be more sensitive to fluctuations in population dynamics. As such, the combination of neutrally- and adaptively-evolving genes may be informative in populations where reductions in abundance have been documented. The European eel (Anguilla anguilla) underwent a drastic and well-reported decline in abundance in the late 20th century and still displays low recruitment. Here we compared genetic diversity indices estimated from neutral (mitochondrial DNA and microsatellites) and adaptive markers (MHC) between two distinct generations of European eels. Our results revealed a clear discrepancy between signatures obtained for each class of markers. Although mtDNA and microsatellites showed no changes in diversity between the older and the younger generations, MHC diversity revealed a contemporary drop followed by a recent increase. Our results suggest ongoing gain of $\mathrm{MHC}$ genetic diversity resulting from the interplay between drift and selection and ultimately increasing the adaptive potential of the species. 


\section{Evaluating the adaptive potential of the European eel: is the}

\section{2 immunogenetic status recovering?}

3 Miguel Baltazar-Soares ${ }^{1}$, Seraina E. Bracamonte ${ }^{1,2}$, Till Bayer ${ }^{1}$, Frédéric J.J. Chain ${ }^{3}$, Reinhold

4 Hanel $^{4}$, Chris Harrod ${ }^{5}$, Christophe Eizaguirre 6

5 1GEOMAR Helmholtz Centre for Ocean Research Kiel, Düsternbrooker Weg 20, 24105 Kiel,

6 Germany

$7 \quad{ }^{2}$ Leibniz-Institute of Freshwater Ecology and Inland Fisheries, Muggelseedamm 310, 12587

8 Berlin, Germany

9 32Department of Biology, McGill University, 1205 avenue Docteur Penfield, Montréal, Québec,

10 H3A 1B1, Canada

11 4Thunen-Institute of Fisheries Ecology, Palmaille 9, 22767 Hamburg, Germany

12 EUniversidad de Antofagasta, Instituto de Ciencias Naturales Alexander von Humboldt, Avenida

13 Angamos 601, Antofagasta, Chile

$14{ }^{6}$ School of Biological and Chemical Sciences, Queen Mary University of London, Mile End Road,

15 London E1 4NS, UK 
 \\ Abstract}

21 The recent increased integration of evolutionary theory into conservation programs has greatly improved our ability to protect endangered species. A common application of such theory links population dynamics and indices of genetic diversity, usually estimated from neutrally evolving markers. Some studies however have suggested that highly polymorphic adaptive genes, such as the immune genes of the Major Histocompatibility Complex (MHC), might be more sensitive to fluctuations in population dynamics. As such, the combination of neutrally- and adaptivelyevolving genes may be informative in populations where reductions in abundance have been documented. The European eel (Anguilla anguilla) underwent a drastic and well-reported decline in abundance in the late $20^{\text {th }}$ century and still displays low recruitment. Here we compared genetic diversity indices estimated from neutral (mitochondrial DNA and microsatellites) and adaptive markers ( $\mathrm{MHC}$ ) between two distinct generations of European eels. Our results revealed a clear discrepancy between signatures obtained for each class of markers. Although mtDNA and microsatellites showed no changes in diversity between the older and the younger generations, MHC diversity revealed a contemporary drop followed by a recent increase. Our results suggest ongoing gain of $\mathrm{MHC}$ genetic diversity resulting from the interplay between drift and selection and ultimately increasing the adaptive potential of the 37 species. 
38 Introduction

39 Preserving natural biodiversity while allowing species to maintain their adaptive potential is a

40 major challenge in modern conservation biology (Frankham et al. 2002). Anthropogenic

41 activities impact global ecosystems and reduce population sizes of species, whether by

42 shrinking or fragmenting available habitats, overexploitation, or disruption of population

43 dynamics (Allendorf et al. 2008; England et al. 2010; Thomas et al. 2004). Small populations are

44 more vulnerable to environmental, demographic and genetic processes (Keith et al. 2008).

45 Genetic factors are particularly important as they may not manifest immediately after

46 population reduction but their effects persist in the population even if the population size

47 recovers to otherwise sustainable levels, e.g. through bottleneck effects (Spielman et al. 2004).

48 Populations display complex evolutionary dynamics and evolutionary genetics offers ideal

49 framework for conservation biologists to monitor population changes and viability (Hendry et

50 al. 2011). Although genetic studies applied to wild populations of non-model species have

51 largely focused on the analysis of neutrally evolving loci (see (McMahon et al. 2014)),

52 conservation managers have expanded their toolbox to include screening of adaptive loci

53 (Hendry et al. 2011). Such measures are required to fill knowledge gaps regarding species'

54 evolutionary and adaptive potential (Eizaguirre \& Baltazar-Soares 2014).

55 The genes of the Major Histocompatibility Complex (MHC) have repeatedly been shown to be

56 suitable candidates to evaluate the immune adaptive potential of endangered populations

57 (Sommer 2005; Stiebens et al. 2013b). This highly polymorphic (high heterozygosity and gene

58 duplications), multigene family (Apanius et al. 1997; Klein et al. 2007) plays a decisive role in 
59

60

61

62

63

64

65

66

67

controlling the vertebrate adaptive immune system by presenting self- and pathogen-derived peptides to T-cells (Janeway et al. 2005). Pathogen-mediated selection is acknowledged to be one of the primary factors of balancing selection maintaining the extreme MHC polymorphism in a population (Eizaguirre et al. 2012a; Piertney \& Oliver 2006; Spurgin \& Richardson 2012). Therefore, investigating shifts in MHC allele frequencies (Eizaguirre et al. 2012b) may be a particularly informative tool as an indirect way to detect the emergence of diseases (Sommer 2005). Similarly, examining how MHC genetic diversity fluctuates in parallel with the incidence of diseases or parasites can provide indirect evidence for the impact of those selective agents on the dynamics of the host population (McCallum 2008). Lastly, MHC genes have also shown to be informative of demographic events, particularly when selection plays an important role in population reductions (Sutton et al. 2011).

The European eel is a highly migratory, semelparous fish whose spawning grounds are located in the Sargasso Sea and whose foraging grounds cover coastal, mixohaline and freshwater habitats (Harrod et al. 2005) across much of Europe and even extend to North Africa and the Levantine coast. The post-hatching early larval transport is first facilitated by local currents in the Sargasso sea, connecting the spawning area with the Gulf Stream (Baltazar-Soares et al. 2014), and by the North Atlantic gyre, that completes the larval migration to the continental shelf (Bonhommeau et al. 2008; Kettle et al. 2008b; Munk et al. 2010). Once larval eels enter shelf waters, they undergo a series of substantial changes in morphology and physiology: individuals become glass eels, with a fusiform, transparent body that facilitates active swimming towards coastal waters (Miller 2009). The duration of the continental life stage varies on the location of growth habitats, and may last from as little as two years (EIFAAC/ICES 2013) 
81 to several decades prior to metamorphose into silver eel. At this stage, energetic reserves are

82 collected to allow sexual maturation and the long spawning migration back to the Sargasso Sea

83 (Tesch 2003).

Although the number of glass eels arriving at continental coasts across Europe experienced a first drop in the 1960s, the major recruitment collapse occurred at the beginning of the 1980s (EIFAAC/ICES 2011). For the subsequent three decades, the recruitment of glass eels has remained as low as 1 to $10 \%$ of the values prior to the 1980s (EIFAAC/ICES 2011). The low recruitment regime is hypothesized to have resulted from multiple impairing factors including productivity changes in the Sargasso Sea (Friedland et al. 2007), habitat degradation including river regulation, pollution and reduced freshwater habitats (Prigge et al. 2013; Robinet \& Feunteun 2002), changes in oceanic currents (Baltazar-Soares et al. 2014; Kettle et al. 2008a), introduction and spread of diseases, such as the EVEX (Van Ginneken et al. 2005) and the swim bladder parasite Anguillicola crassus (Kirk 2003), resulting in a severe lack of spawners (Dekker 2003). Experimental studies focusing on this invasive nematode for instance revealed that the European eel is unable to mount an effective immune response, thus becoming particularly susceptible to infection (Knopf 2006).

97 The European eel is currently considered a single panmictic population (Als et al. 2011; Pujolar et al. 2014), even though punctual deviations from panmixia have been reported (BaltazarSoares et al. 2014; Dannewitz et al. 2005; Wirth \& Bernatchez 2001). While the vast majority of genetic studies have focused on solving the population structure of the species, few have tried to determine the impact of the recruitment decline on the species' genetic diversity (Pujolar et 
102 al. 2011; Pujolar et al. 2013; Wirth \& Bernatchez 2003). Studies that aimed at doing so have 103 evaluated neutrally evolving genetic markers. In 2003, Wirth and Bernatchez (Wirth \& 104 Bernatchez 2003) analyzed 7 microsatellite loci in 611 European eel individuals and reported no 105 measurable signature of the 1980s recruitment decline. In 2011, Pujolar and coworkers (Pujolar 106 et al. 2011) analyzed the diversity of 22 microsatellite markers on 346 individuals. Again, 107 genetic signature of a population reduction was absent. It was therefore suggested that the 108 1980s decline, although marked in terms of population biology was not sufficiently extreme to affect the diversity of these polymorphic and neutrally evolving loci (Pujolar et al. 2011). Employing a genome-wide reduced representation sequencing technique (RAD) - that identified in its vast majority neutral markers - Pujolar et al. (Pujolar et al. 2013) did not detect

112 either evidence for a recent decline of genetic diversity to be associated with the drastic drop in recruitment (Pujolar et al. 2013).

114 Here, we expand on these studies detailing an extensive evaluation of the current genetic 115 status of the European eel species, which includes 1) screening of both neutral and adaptive 116 markers and 2) a temporal approach directly comparing two distinct generations of eels. A

117 temporal approach is regarded as a key requirement when investigating the signature of 118 demographic events on genetic diversity in a wild population (Sutton et al. 2015). Specifically 119 for the eel system, evaluating genetic diversity in two distinct, non-overlapping age cohorts is 120 important since the major component of genetic distribution of nuclear markers in this species 121 seems to relate to different age cohorts (Dannewitz et al. 2005).

\section{Material and methods}




\section{Study scheme}

124 A total of 683 eels were analyzed in this study, 202 of which corresponded to mature silver eels

125 caught in freshwater while undertaking their spawning migration. The other 481 individuals

126 were glass eels collected from 2009 to 2012 immediately upon their arrival in coastal waters

127 (Fig. S1). Number of individuals per sampling site, year of capture, developmental stage, and geographical locations can be found in Table 1. Note, we mostly sampled in one catchment per country and used countries' acronyms to refer to the locations where the specimens were collected. All samples were included in the analyses of mtDNA and microsatellites. Although the main objective of this work was to evaluate the genetic status of the eel species on a temporal scale, we also analyzed spatial patterns of genetic differentiation for comparison with previously published studies (Als et al. 2011; Maes \& Volckaert 2002; Pujolar et al. 2014; Wirth

\& Bernatchez 2001).

Amongst the 683 individuals, 327 were sequenced at the exon 2 of the MHC class II B gene. This number was achieved as a compromise between costs of 454 sequencing and the need to provide sample sizes sufficient to provide a robust screen for spatial and temporal patterns of local adaptation. Locations and respective sample sizes of fish screened for the MHC gene are highlighted in Fig. S2. Temporal analyses were performed after dividing the dataset in two distinct age groups: the older "silver eels" age group and the younger "glass eels" group. The

141 first group included individuals born soon after the drop in recruitment (late 1990s and early

142 2000s) while the second group consisted of very recently recruited individuals (2009 onwards)

143 (ICES 2015). DNA was extracted from fin clips ("silver eels") or tail clips ("glass eels") with 
144 Qiagen DNeasy Kit ${ }^{\odot}$ Blood and Tissue kit (Hilden, Germany) following the manufacturer's 145 protocol.

\section{Neutrally evolving mitochondrial marker}

\section{Genetic estimates of diversity, population differentiation and demography}

148 All 683 glass eels were sequenced using Sanger sequencing for the mitochondrial NADH

149 dehydrogenase 5 (ND5) exactly replicating (Baltazar-Soares et al. 2014). Haplotype diversity $150(H d)$ and nucleotide diversity $(\pi)$ were calculated for each sampling location in DnaSP v5

151 (Librado \& Rozas 2009). Genetic structure was estimated using Arlequin v3.5 with 10.000 152 permutations (Excoffier \& Lischer 2009). Moment-based demographic parameters that test for 153 changes in effective population size were calculated for each sampling location in DnaSP v5 154 under the assumption of mutation-drift equilibrium. Tajima's $D$ (Tajima 1989) and raggedness' $r$ 155 (Rogers \& Harpending 1992) were also calculated in DnaSP v5. Ninety-five percent confidence 156 intervals were estimated through coalescence simulations using 1.000 permutations. We 157 evaluated the nucleotide mismatch pairwise distributions within each geographical location 158 (Rogers \& Harpending 1992). These distributions were compared to expected distributions 159 under a constant population size and sudden population expansion (Librado \& Rozas 2009).

160 Neutrally evolving nuclear markers

161 Genetic estimates of diversity, differentiation and demography amongst 162 freshwater locations 
163 All samples were genotyped for twenty-two microsatellite loci optimized from previous studies 164 (Als et al. 2011; Pujolar et al. 2009; Wielgoss et al. 2008b). Amplification took place in four PCR 165 multiplexes of four to six loci each. Specifically: multiplex $\mathrm{A}-55^{\circ} \mathrm{C}$ annealing temperature 166 included CT77, CT87, CA55, CA58, CT68, and AJTR-37; multiplex B - 55 ${ }^{\circ} \mathrm{C}$ annealing temperature 167 - included CT82, CT76, CT89, CT59, CA80, and CT53; multiplex C - $60^{\circ} \mathrm{C}$ annealing temperature 168 - included C01, M23, AJTR-45, AJTR27, I14, and 008; multiplex D - $60^{\circ} \mathrm{C}$ annealing temperature 169 - included AJTR-42, B09, B22, and N13. All reactions were performed in a total volume of $10 \mu \mathrm{l}$ 170 and followed the QIAGEN ${ }^{\odot}$ Multiplex PCR kit's recommendations. Genotyping was performed 171 on an $\mathrm{ABI}^{\odot} 3100$ Genetic Analyzer. Alleles were called in GENEMARKER $^{\odot}$ v. 1.91 (Softgenetics 172 LLC, State College, PA).

173 Nei's unbiased heterozygosity $(\mathrm{He})$, observed heterozygosity $(\mathrm{Ho})$ and $\mathrm{F}_{\mathrm{IS}}$ were calculated for 174 each sampling location in GENETIX (1.000 bootstrap, (Belkir K 1999)). Rarefied allelic richness 175 (Ar) was calculated for each sampling location in HP-RARE v1.0 (Kalinowski 2005). Genetic 176 structure amongst sampling locations was inferred through pairwise comparisons in Arlequin 177 v3.5 and Bayesian clustering in STRUCTURE v2.3.3 (Pritchard et al. 2000). STRUCTURE was run 178 assuming a maximum number of possible groups of $K=26$, i.e. representing the sum of all spatial and temporal partitions of our sample, with 10000 MCMC repeats after a 1000 burn-in while assuming an admixture model with correlated allele frequencies. Three iterations were 181 performed for each $\mathrm{K}$.

182 Genetic signatures of a bottleneck were tested for each location using the tests available in 183 BOTTLENECK (Cornuet \& Luikart 1996). These methods are sensitive to recent and severe 
184 reductions on effective population size $\left(N_{e}\right)$ (Cornuet \& Luikart 1996). A two-phase mutation

185 model was assumed with $10 \%$ of the loci allowed to evolve through stepwise mutation (Kimura

186 \& Ohta 1978). Allele frequency distributions were also calculated for each location.

187 Genetic estimates of diversity, differentiation and demography - inter188 generation level

189 In order to compare genetic diversity and demographic histories between the two cohorts and 190 to avoid sampling bias from disproportionate number of samples in the two eel age groups

191 ("glass eels" $\mathrm{n}=481$ and "silver eels" $\mathrm{n}=202$ ), we performed 10 rounds of re-sampling of the data 192 without replacement using PopTools (Hood 2010), hereafter referred to as "replicates".

193 Replicates were performed based on 50 individuals. This standardization is critical to validate

194 future comparisons, as it has been long acknowledged that sample size affects the detection of 195 genetic signatures of recent bottlenecks (Luikart et al. 1998) and the estimation of effective 196 population size (Waples \& Do 2010).

197 Deviations from Hardy-Weinberg equilibrium (HWE) were calculated for each replicate in 198 Arlequin v3.5 (10 000 permutations). Nei's unbiased heterozygosity (He), observed 199 heterozygosity $(\mathrm{Ho})$, allelic richness $(\mathrm{Ar})$ and $\mathrm{F}_{\mathrm{IS}}$ were calculated and compared between groups 200 of replicates, i.e. "glass eels" and "silver eels", with two-sided t-tests in FSTAT (1000 201 permutations) (Goudet 1995). The distribution of genetic variance between "glass eels" and 202 "silver eels" was assessed with an analysis of molecular variance (AMOVA, Arlequin v3.5) 203 amongst groups of replicates. Demographic history was inferred using two approaches. First, 204 we evaluated the possible genetic signature of the recent population decline using BOTTLENECK 
205 (1000 iterations) for each age group as previously described. Second, we estimated the 206 effective population size $\left(N_{e}\right)$ of each replicate of "silver eels" and "glass eels" using the linkage207 disequilibrium method implemented in NeEstimator V2.01 (Do et al. 2014). We utilized $P_{\text {crit }}=$ 208 0.05, since lower $P_{\text {crit }}$ can overestimate Ne (Waples \& Do 2008). All estimates were obtained 209 with the composite Burrows method (Weir 1990). The unweighted harmonic mean was

210 calculated for each group according to the following equation: $\widehat{N}_{e}=\frac{j}{\left.\sum_{i=1}^{j}\left(1 / N_{e(i)}\right)\right)}$ where $j$ is the 211 number of replicates, $i$ is a given replicate and $N_{e(i)}$ is the $N_{e}$ estimate of the ith replicate 212 (Waples \& Do 2010).

\section{Adaptive marker: diversity and demography of the MHC}

214 We amplified the exon 2 of the MHC class II gene that encodes for the peptide-binding groove 215 of the molecule following protocols optimized for the European eel (Bracamonte et al. 2015). We used the forward primer AaMHCIIBE2F3 (5'- AGTGYCGTTTCAGYTCCAGMGAYCTG-3') and

217 reverse primer AaMHCIIBE2R2 (5'- CTCACYTGRMTWATCCAGTATGG-3') which allow the 218 amplification of different allelic lineages of the MHC class II $\beta$ genes (Bracamonte et al. 2015). Sequencing was performed on a $454^{\odot}$ platform at LGC genomics (Belgium) following (Stiebens et al. 2013a; Stiebens et al. 2013b). Briefly, two independent reactions were prepared for each

221 individual. After a first PCR of 20 cycles, a reconditioning step (dilution 1:5) was performed, and 222 the template was used for a second PCR of 20 cycles. The reconditioning step combined with 223 independent reactions was shown to significantly decrease the number of PCR artifacts (Lenz \& 224 Becker 2008) and facilitate allele call (Stiebens et al. 2013a). The second set of PCR was 225 performed using the specific MHC primers extended by the 454 adaptors and a 10 bp individual 
226 tag. Allele calling and respective assignment to individuals followed (Stiebens et al. 2013a;

227 Stiebens et al. 2013b) and primarily relied on matching alleles present in both independent

228 reactions (Sommer et al. 2013). Genotyping using this method has previously been compared to

229 Sanger sequencing and showed its high accuracy (Bracamonte et al. 2015). Even though

230 variants may stem from different loci, we will refer to them as alleles hereafter.

231 Individual MHC allele numbers detected from the different paralogs, nucleotide diversity, and

232 individual average nucleotide p-distance (Eizaguirre et al. 2012a) were calculated for each

233 sampling location and for each group, i.e. "silver eels" and "glass eels", in DnaSP v5 and using

234 custom Perl scripts. MHC allele pools were compared amongst sampling locations and between

235 "silver eels" and "glass eels" with analyses of similarity (ANOSIM) using Primer v6 (Clarke 1993)

236 following (Eizaguirre et al. 2011) 1000 permutations). Correlation between MHC divergence and

237 neutral structure was calculated using a Mantel test between pairwise $F_{\text {ST }}$ matrices (mtDNA and

238 microsatellites) and pairwise Bray-Curtis similarity matrices (MHC).

239 Minimum number of recombination events $(R m)$ and estimates of recombination rate $(R)$ were

240 calculated in DnaSP v5 (Hudson \& Kaplan 1985), as well as the relative (R/O) contribution of

241 recombination $(R)$ and point mutations $(\theta)$ in the generation of genetic diversity (Reusch \&

242 Langefors 2005). Gene conversion was investigated using $\psi$ that measures the probability of a

243 site to be informative for a conversion event $(\psi>0$, (Betran et al. 1997)) between "glass eels"

244 and "silver eels", using a sliding window method (window length = 2, step size $=1$ ) implemented 245 in DnaSP v5. 
246 In order to test for the mode of evolution of the MHC in A. anguilla, overall positive selection

247 was estimated with a Z-test implemented in MEGA v5 (Tamura et al. 2011). We tested for signs

248 of codon-specific positive selection using maximum likelihood site models with CODEML

249 implemented in PAML v4.4 (Yang 2007) and the mixed effects model of evolution (MEME)

250 (Murrell et al. 2012) implemented in the Datamonkey web server (Delport et al. 2010; Pond \&

251 Frost 2005). The maximum likelihood procedures evaluate heterogeneous ratios ( $\omega$ ) among

252 sites by applying different models of codon evolution. Three likelihood-ratio tests of positive

253 selection were performed comparing the models M1a (nearly neutral) vs M2a (positive

254 selection), $M 7(\beta)$ vs $M 8(ß+\omega)$, and $M 8 a(\beta+\omega=1)$ vs $M 8$ (Yang 2007). In the models $M 2 a$ and

255 M8, positively selected sites are inferred from posterior probabilities calculated by the Bayes

256 inference method (Yang et al. 2005). We further tested for sites that experienced episodic

257 events of positive selection by using MEME. This model considers that $\omega$ varies between sites

258 (fixed effect), and between branches at a site (random effect) (Murrell et al. 2012). The null

259 expectation is that all branches have $\omega<1$. In short, this model allows each site to have its own

260 selection history, contrary to fixed effect models (as the ones implemented in CODEML) that

261 assume constant selective pressures within a branch (Murrell et al. 2012).

262 To assume selection as the main evolutionary mechanism responsible for changes in genetic 263 diversity, sites under positive selection were concatenated for downstream analyses (Positively

264 Selected Sites, PSS). Theoretically, sites interacting with parasite-derived antigens are expected

265 to be under positive selection while other sites, within the same exon, may evolve differently

266 but still maintain the integrity of the MHC molecules. Therefore, we also concatenated the

267 remaining sites (nPSS) and performed identical analyses as for the PSS. Nucleotide mismatch 
268 pairwise distributions were calculated for PSS and nPSS of both "silver eels" and "glass eels"

269 under the assumptions of a constant population size and sudden expansion using DnaSP v5. The

270 historical profile of MHC genetic diversity was investigated with Bayesian skyline plots (BSP)

271 (Drummond et al. 2005) in BEAST v1.8 (Drummond \& Rambaut 2007). Although these statistical

272 procedures are often used to infer demographic events based on fluctuations of neutral genetic

273 diversities, they have also been used to estimate the strength of adaptive evolution at the

274 organism level (Bedford et al. 2011), and of functional genomic regions (Padhi \& Verghese 275 2008).

276 Because of several expected characteristics of the $\mathrm{MHC}$, including a deviation from a neutral

277 mode of evolution, recombination or gene conversion events (Spurgin et al. 2011) and trans-

278 species polymorphism (Lenz et al. 2013) that also occurs in this species (Bracamonte et al.

279 2015) as well as the existence at least three loci (Bracamonte et al. 2015), we did not attempt

280 to associate the substitution rate to a clock-calibrated evolution. As such, we fixed a molecular

281 clock and assumed three different mutation rates: 0.2, 1 (the default parameter) and 5

282 substitutions per time unit respectively. The substitution model was chosen in jModeltest

283 (Tamura-Nei: Tn93) (Darriba et al. 2012; Guindon \& Gascuel 2003) and also inserted as

284 parameter in BEAST's runs. Markov chain run was set to a length of $1 \times 10^{8}$. The historical

285 profile of MHC diversity was reconstructed for PSS and nPSS of both "silver eels" and "glass

286 eels". Piecewise constant skyline model allowing for five skyline groups were used in three

287 independent MCMC runs to verify consistence in parameter space. We then compared the

288 marginal probability distributions of several parameters amongst the runs. Lastly, we 
289 constructed lineage-through-time plots. These plots reflect accumulation of lineages through

290 time translated for a given dated phylogeny (Nee et al. 1992).

291 Results

292 Neutrally evolving mitochondrial DNA

293

294

295

296

297

298

299

300

301

302

303

304

305

306

307

\section{Molecular indices, population structure and demography amongst sampling}

\section{locations}

Analyses of $355 \mathrm{bp}$ of the mtDNA ND5 in 683 European eels revealed 102 haplotypes including 73 singletons (Data S1). Forty-eight randomly picked singletons were verified by independent extraction, amplification and re-sequencing to eliminate possible risks of sequencing errors. After we eliminated the possibility of sequencing errors (48 out of 48 singletons were verified by independent sequencing) we included all 73 singletons in the subsequent analyses. Amongst sampling locations, haplotype diversity ranged between 0.575 (BU) and 0.934 (GL). Nucleotide diversity ranged between $0.003\left(G_{-} S P A\right)$ and $0.008(G L)$, with an average of 0.005 ( \pm 0.001$)$ amongst sampling locations (Table 1). Pairwise $\mathrm{F}_{\mathrm{ST}}$ comparisons computed from haplotype frequencies amongst the 26 geographically confined groups revealed 17 significant pairwise differentiations however none passed corrections for multiple tests following the false discovery rate (threshold $p=0.013$ for 26 tests (Narum 2006)). All results are shown in Table S1.

Tajima's $D$ values were negative amongst almost all sampled locations, suggestive of population expansion or of population subdivision (Tajima 1989). The three exceptions were GER 
308 (Germany), which belongs to a closed system, the Schwentine river, where recruitment is solely

309 mediated by stocking (Prigge et al. 2013), as well as G_TITA (Italy) and G_WENG (England),

310 where the values might reflect artificial stochasticity due to low sample sizes. Mismatch

311 distribution analyses performed at the population level showed the typical pattern of a

312 historical population expansion where the peak differs from zero (Rogers \& Harpending 1992),

313 Fig. 1a).

\section{Molecular indices, population structure and demography between generations}

315 Haplotype diversity and genetic diversity between "silver eels" and "glass eels" were very

316 similar: $H d_{\text {silver eels }}=0.821, H d_{\text {glass eels }}=0.842 ; \pi_{\text {silver eels }}=0.0048, \pi_{\text {glass eels }}=0.0049$. No evidence

317 for temporal genetic structure based on haplotype frequency distributions was detected

318 between these groups, $F_{S T}=0.000, p=0.138$. Both groups also had negative and significant

319 Tajima indices: $D_{\text {silver eels }}=-2.053, D_{\text {glass eels }}=-2.357$, both $\mathrm{p}<0.05$ (Table 2). Mismatch distribution

320 analyses revealed that both "silver eels" and "glass eels" display the distribution of expanding

321 populations, suggesting that the overall pattern is not driven by a single generation and has a

322 true biological origin visible in both cohorts (Fig. 2). 
323 Neutrally evolving nuclear markers

\section{Molecular indices, population structure and demography amongst locations}

325 Across populations, He ranged between 0.687 (G_NIRL) and 0.758 (PT), Ho between 0.557

326 (G_TITA) and 0.667 (DK) and the average number of alleles per locus varied between 3.546 327 (G_VFRA) and 15.773 (G_AD2012). Allelic frequencies are reported in Data S2. Fis varied

328 between 0.0380 (G_NIRL) and 0.254 (Q) (Table S1). Even though $\mathrm{F}_{\mathrm{ST}}$ estimates are very low, 329 pairwise comparisons revealed 7 statistically significant pairwise comparisons after correcting 330 for multiple testing (Table S1). Since six of those included comparisons between locations with 331 low sample size, i .e. G_NIRL, G_WENG, G_TITA or G_BNIRL, the significance could be attributed 332 to stochasticity due to low sample sizes. STRUCTURE analyses did not show any signs of 333 population clustering as expected under the weak observed differentiation (Fig. S3).

334 None of the sampled locations showed either heterozygote excess or a mode shift in allele 335 frequencies, genetic signatures characteristic of population bottlenecks (Fig. 1b).

\section{Molecular indices, structure and demography between generations}

337 Twenty-one loci were used to analyze "silver eels" and "glass eels" as locus AjTr-45 consistently 338 deviated from Hardy-Weinberg equilibrium in all "silver eels" replicates. No significant 339 differences between generations were apparent for $\mathrm{He}\left(\mathrm{He}_{\text {silver eels }}=0.744, \mathrm{He}\right.$ glass eels $=0.743, \mathrm{p}$ $340=0.54), \operatorname{Ar}\left(A r_{\text {silver eels }}=11.74, \operatorname{Ar}\right.$ glass eels $\left.=11.83, \mathrm{p}=0.46\right)$ and $\mathrm{F}_{\mathrm{IS}}\left(\mathrm{F}_{\mathrm{IS} \text { silver eels }}=0.165, \mathrm{~F}_{\mathrm{IS} \text { glass eels }}=\right.$ $3410.162, p=0.07)$. Ho, however, was significantly higher in the "silver eel" group ( $H_{0}$ silver eels $=$ 342 $\left.0.621, \mathrm{Ho}_{\text {glass eels }}=0.612, \mathrm{p}<0.01\right)$. The AMOVA between "silver eel" and "glass eel" groups of 
343 replicates revealed a pattern of isolation by time $\left(F_{C T}=0.002, p<0.001\right)$, supporting our a-priori

344 assumption that those groups represent clear age structured cohorts.

345 None of the replicates showed evidence of heterozygote excess or deficiency. Averaged allele

346 frequencies of neither "silver eels" nor "glass eels" deviated from an expected L-shape

347 distribution (Fig. S3). However, we found that the averaged allele frequencies distribution

348 observed in the "silver eels" group showed the signature of a 5-generations-old bottleneck

349 identified from computer simulations (Luikart et al. 1998). This is particularly evident in the

350 distribution of the two most common allele classes, 0.8-0.9 and 0.9-1.0. This signature was not

351 visible anymore in the "glass eel" group (Fig. S4).

352 Estimates of effective population size $\left(N_{e}\right)$ amongst replicates ranged between $0-625.2$ for

353 "silver eels" and 0 - 2708.9 for "glass eels". The harmonic mean of effective population size

354 estimates amongst replicates, $\hat{N}_{\text {e, }}$ resulted in $480.9<\hat{N}_{\text {e silver eels }}<2941.7$ and $1380.2<\hat{N}_{\text {e glass eels }}<$ 3553506.0 (Table S2).

\section{Adaptive marker: the MHC}

\section{Molecular indices and population structure}

358 We sequenced a $247 \mathrm{bp}$ fragment of the exon 2 of the MHC class II region (91\% of the total size

359 of the exon) in 327 individuals using 454 sequencing technology. We detected 229 different

360 amino acid coding variants. Among those, 226 (98\%) were found to be unique in the dataset

361 but present in both independent replicated reactions and therefore kept as true variants (Data

362 S3). A total of 116.276 sequence reads were used in this study. Amongst locations, MHC 
363 nucleotide diversity ranged between 0.102 (LL) and 0.138 (BT). The mean number of alleles per

364 individual ranged between $2(\mathrm{Q}, \mathrm{SE}=0.298)$ and $4\left(\mathrm{G} \_\mathrm{BU}, \mathrm{SE}=0.392\right)($ Table $\mathrm{S} 3)$ and revealed to 365 overall significantly differ amongst sampled locations $\left(F_{17}=1.674, p=0.046\right)$. However, post-

366 hoc pairwise comparisons showed no significant differences between pairs of populations after 367 correction for multiple testing (all $p>0.05$ ). The mean nucleotide divergence ( $p$-distance) ranged 368 between $0.078(\mathrm{BL})$ and $0.141(\mathrm{FI})$ (Table S4) and was significantly different among sampled 369 locations $\left(\mathrm{F}_{17}=1.860, \mathrm{p}=0.021\right)$. Post-hoc pairwise comparisons revealed two significant 370 comparisons after correction for multiple testing (GER vs FI, t $=-3.551, \mathrm{p}=0.045$, GER vs 371 G_AD2011, $t=-3.961, p=0.010)$, suggesting a reduced MHC diversity the stocked freshwater 372 system of the Schwentine river, in Germany.

373 The ANOSIM showed no significant differences in MHC allele pools amongst populations $374(R=0.001, p=0.98)$. Overall, no correlation was found between Bray-Curtis similarity matrices 375 on $\mathrm{MHC}$ and pairwise $\mathrm{F}_{S T}$ for both mtDNA $\left(R^{2}<0.0001, p=0.58\right)$ and microsatellites $\left(R^{2}<0.0001\right.$, $376 p=0.62)$.

377 Between generations, no difference in $\mathrm{MHC}$ allele pools were observed $(\mathrm{R}=-0.011, \mathrm{p}=0.87)$. 378 Interestingly, "glass eels" had a significantly higher individual mean number of alleles ("glass 379 eels"= 3.423, SE = 0.166; "silver eels "= 2.856, $\mathrm{SE}=0.101 ; \mathrm{F}_{1}=8.819, \mathrm{p}=0.003$ ) and a 380 significantly higher individual mean nucleotide $p$-distance ("glass eels" $=0.117, \mathrm{SE}=0.006$; 381 "silver eels" $\left.=0.101, \mathrm{SE}=0.004 ; \mathrm{F}_{1}=4.577, \mathrm{p}=0.032\right)$ (Table 3). Both the nucleotide diversity $(\pi)$ 382 and the number of minimum recombination events $(R m)$ detected between "silver eels" and 
383 "glass eels" were $\operatorname{similar}\left(\pi\right.$ glass eels $=0.118, \pi$ silver eels $\left.=0.123 ; R m_{\text {silver eels }}=11 ; R m_{\text {glass eels }}=10\right)$

384 while the $R / \theta$ ratio was slightly higher in "silver eels" $\left(R / \theta_{\text {silver eels }}=2.174 ; R / \theta_{\text {glass eels }}=2.089\right)$. 
385 Screening for novel genetic diversity through events of gene conversion

386 Gene conversion segments with an average nucleotide length of $4 \mathrm{bp}$ were detected within the

387 "glass eels" group but not in the "silver eel" group. The average $\psi$ of the whole segment was

388 found to be 0.0002 (Fig. 3). This value is high enough to ascertain the occurrence of conversion

389 events, but not robust enough to determine the exact length of the observed tracts (Betran et 390 al. 1997).

391 Testing for positive selection

392 Model-based tests using CODEML revealed 11 sites under positive selection while MEME 393 identified 27 sites that have experienced episodic events of positive selection (Table S6). The 394 discrepancies between the two methods reflect the different assumptions underlying the fixed 395 effect models implemented in CODEML and the mixed effect models of MEME. Positively 396 selected sites detected by both methods matched 10 out of 19 antigen binding sites identified 397 in humans by X-ray crystallography (Reche \& Reinherz 2003) (Fig. 3, Text S1). Due to the 398 functional role of the MHC, all amino acid sites that have experienced at least episodic events 399 of selection were selected for further analyses (Fig. 3)

Demography and historical profile of MHC genetic diversity

401 All mismatch distributions indicated a clear deviation from a constant population size, fitting a 402 scenario where a major demographic event occurred (Fig. 4 and Fig. 5). The frequency 403 distribution of pairwise differences showed different peaks for both PSS (Fig. 4) and nPSS (PSS 404 pairwise differences $=20 ; n P S S$ pairwise differences $=10$ ) (Fig. 5). Those peaks reflect old lineages that are 405 maintained in genes exhibiting trans-species polymorphism as is expected of the MHC (Klein et 
406 al. 2007) and recently reported for the European eel (Bracamonte et al. 2015). It was also

407 possible to observe peaks in PSS and nPSS in the frequency of pairwise differences equaling 1.

408 Those peaks are suggestive of increases in genetic diversity. No differences in the demographic 409 profiles were detected between "silver eels" and "glass eels" (Fig. 4 and Fig. 5).

410 Bayesian demographic reconstructions revealed a steep decline in genetic diversity that

411 occurred close to the present time. This pattern is characteristic of a genetic bottleneck and is

412 shared by all reconstructions independently of the substitution rates (Fig. 4). However, lineage-

413 through-time plots reveal a very recent burst of lineage diversification, also at $\mathrm{t}=0$ and common

414 to both generations (Fig. 6). The three independent MCMC runs clearly overlap for the 415 distributions of the posterior, likelihood and skyline estimates (Fig. S5), assuring that the 416 profiles observed were not a product of the Bayesian stochasticity, but rather a real and 417 reproducible pattern.

\section{Discussion}

419 We investigated how the steep decline in European eel recruitment observed in the 1980s and 420 subsequent population reduction may have affected this species' genetic diversity. We 421 expanded on previous studies (Pujolar et al. 2011; Pujolar et al. 2013; Wirth \& Bernatchez 2003)

422 and searched for contemporary signature of a population reduction by considering neutral 423 markers (mtDNA or microsatellites) as well as a highly polymorphic region of the immune genes 424 of the MHC. Although MHC is an excellent marker to evaluate genetic diversity, as a proxy for 425 adaptive potential, in endangered populations (Sommer 2005; Sutton et al. 2015), no formal 426 study of its variation and evolution exist for the European eel. 
427 Location-specific patterns of genetic diversity and demographic

\section{8 estimates}

429 Although it was not the primary focus of this study, spatial comparison of mtDNA genetic diversity provided information on the genetic differentiation amongst continental locations.

431 Under neutrality, haplotype and nucleotide diversities are predicted to be a function of 432 population size (Frankham et al. 2002). Therefore, in the drastically declined European eel 433 population, we expected to find an overall low genetic diversity. Furthermore, and due to 434 reports of panmixia (Als et al. 2011), we also expected coherent patterns amongst sampled 435 locations. Instead, we found variation in nucleotide diversity (0.003-0.008), haplotype diversity $436(0.575-0.934)$ and Tajima's $D$ estimates amongst locations. The high variation in genetic indices 437 amongst geographical areas suggests that processes act differently across the continental 438 distribution of the European eel. Our observations may result from the post-hatching 439 transatlantic migration, since simulations showed variability in spawning grounds would leave genetic signatures across continental locations under low recruitment (Baltazar-Soares et al. 441 2014). Conversely, it could be explained by a scenario where mtDNA haplotypes are linked to 442 genes under single-generation local selection (Pujolar et al. 2014). In this scenario, selection would act mainly in the local foraging environment, and not in the spawning ground, with 444 specific pressures sorting out genotypes in given locations. Expanding the study towards a more 445 genomic approach with adult fish sampled from the spawning ground would reveal further 446 insights into the most prominent scenario. 
447 Due to high levels of polymorphism, neutrally evolving microsatellites are thought to be 448 sensitive enough to detect subtle shifts in population dynamics (England et al. 2010). Here as 449 well, we hypothesized that the chronically low recruitment in European eel observed since the 450 1980s had negatively affected estimates of genetic diversity in a coherent spatial pattern.

451 Estimates of allelic richness $(\mathrm{Ar}=2.710-2.960)$ and heterozygosity estimates $(\mathrm{He}=0.687-0.758)$

452 were very similar, and neither mode shifts nor heterozygote excesses were observed (Fig. 1 and 453 Fig. S1). These results are in line with a previous study (Pujolar et al. 2011), which was 454 conducted focusing on 12 locations ( 3 locations sampled across a temporal range) and that 455 employed 22 EST-linked microsatellites. The apparent homogeneity of the allelic indices 456 amongst locations matches the expectations based on neutral nuclear markers for a panmictic 457 population where successfully recruited mature fish would mate randomly in the spawning 458 ground (Als et al. 2011). Note, after correction for multiple testing, we detected significantly 459 different pairwise $\mathrm{F}_{\mathrm{ST}}$ estimates amongst some locations. Although this could suggest deviations 460 from panmixia, it is likely this pattern is linked to stochasticity due to low sample sizes in those 461 locations (G_NIRL, G_TITA and G_WENG).

462 Regarding the MHC, we found differences in the mean number of alleles amongst locations 463 although none of the post-hoc pairwise comparisons revealed to be significant after correction 464 for multiple testing. MHC allele pool composition did not vary amongst sampled locations. We 465 found that the mean nucleotide distances vary amongst locations, but only comparisons 466 between the German populations and two other sampled locations revealed to be significant 467 after correction for multiple testing (Germany vs Finland, Germany vs France2011). Whether it 468 relates to the fact that those samples correspond to a freshwater system, the Schwentine in 
469 Germany, where all eels are stocked remains to be investigated. Stocking however might be an

470 issue in other sampling areas as well and therefore understanding why this population

471 demonstrates a reduction in diversity should be the focus of further studies.

472

\section{Genetic diversity and demographic estimates between age cohorts}

474

475

\section{Recruitment decline of the 1980s did not affected genetic estimates of neutral}

\section{evolving markers}

The major objective of this study was to compare patterns of temporal variation of genetic diversity post-recruitment collapse observed in the 1980s. Here as well, our mitochondrial DNA results showed i) no evidence for a genetic bottleneck, ii) no differences in haplotype and nucleotide diversities between "silver eels" and "glass eels", and iii) no signature of bottleneck in the frequency distribution of pairwise mismatches. The later rather points towards an historical population expansion (Rogers \& Harpending 1992). Given the low variability of the mtDNA marker - in comparison with the set of highly polymorphic microsatellites and $\mathrm{MHC}$ gene - we suggest that such an event extends back in time to a scenario of expansion related to ice-sheet retreat after the last glacial maxima, as previously proposed for such a pattern (Jacobsen et al. 2014).

Investigating the distribution of the genetic variance observed at microsatellites, we found significant differentiation between "silver eels" and "glass eels" replicates. This pattern of genetic variance distribution is in line with previous reports that also attributed higher genetic 
489

490

491

492

493

494

495

496

497

498

499

500

501

502

503

504

505

506

507

508

509

variance amongst temporal, rather than spatial, partitions of $A$. anguilla along the European coasts (Dannewitz et al. 2005). It also confirmed our a-priori assumption of each group representing a distinct generation, and therefore excludes possible confounding factors associated with overlapping generations from the interpretation of demographic estimates (Cornuet \& Luikart 1996; Waples \& Do 2010). Note, even though less likely, we cannot exclude that this observed structure also relates to a spatially structured spawning area of this species (Baltazar-Soares et al. 2014; Dannewitz et al. 2005).

Using microsatellites, we detected no evidence of heterozygote excess in any of the replicates, nor any differences between allelic richness of "silver eels" and "glass eels". This supports previous reports that the recruitment collapse and subsequent low abundance of the eel population did not leave the expected genetic signatures of reduced genetic diversity (Pujolar et al. 2011) suggestive of a system which replenishes genetic diversity rapidly.

However, in-depth demographic analyses suggest that the eel effective population size might actually not be stable. Several lines of evidence support this interpretation: firstly, we estimated $\sim 20 \%$ higher effective population size in "glass eel" replicates (harmonic mean $\left.N_{e}=3506.0\right)$ compared to "silver eels" ( $\left.N_{e}=2941.7\right)$. These contemporary estimates are near the lower confidence intervals of historic effective population sizes previously reported $\left(5000<N_{e}\right.$ <10000; (Wirth \& Bernatchez 2003), but within contemporary estimates of $3000<N_{e}<12000$ (Pujolar et al. 2011)). Noteworthy, the confidence intervals calculated in this study for each generation overlap, raising the need to cautiously interpret those results. Secondly, we observed fewer alleles in the most frequent class of allele frequencies in "silver eels". The 
510 apparent reduction of the most frequent allele class may suggest that the species demography

511 is experiencing a transitory stage from a severe bottleneck, partly detected in "silver eels". It is

512 important to mention that such a signature would only be detected under a severe population

513 reduction a few generations in the past. Hence, we could speculate that the hypothetical

514 bottleneck detected only in "silver eels" may relate to the drops in European eel recruitment

515 that occurred in the beginning of the 1960s (EIFAAC/ICES 2011). It is possible that the 1960s low

516 recruitment had a major impact on the overall genetic diversity of the species. By the crash in

517 the 1980s, the population would have already been depleted from its original genetic diversity,

518 at least for neutrally evolving markers. Such a scenario requires further studies to be confirmed

519 and would rely on historical samples to be analyzed.

\section{MHC reveals signatures of selection}

521 Extending the evaluation of genetic diversity to the evolutionary analysis of the adaptive

522 immune genes of the MHC was motivated by two main reasons. The first relates to studies

523 suggesting MHC diversity to be more sensitive than neutrally evolving markers in the detection

524 of demographic shifts (Sommer 2005; Sutton et al. 2011). The second relates to the invasion of

525 European freshwater systems by the nematode parasite, Anguillicola crassus, for which the

$526 \mathrm{MHC}$ was found to respond to in the paratenic host, the three-spined stickleback (Eizaguirre et

527 al. 2012b). Using the exon 2 of the MHC class II $\beta$ gene, we evaluated 1) genetic diversity, which

528 might have been affected by the recruitment collapse and subsequent population reduction

529 and 2) allele frequency shifts between generations which would be a signature consistent with

530 directional parasite-mediated selection. 
531 Using next-generation sequencing, we identified a total of 229 MHC alleles amongst 327

532 individuals. This indicates that the diversity within this species is not low and directly compares

533 to observations made in wild populations of other fishes that are not qualified as endangered,

534 such as for instances, the half-smooth tongue sole (88 MHC class II alleles amongst 160

535 individuals) (Du et al. 2011). Noteworthy, the characterization of the MHC class II genes in this

536 species revealed that up to six different alleles may exist per individual, suggesting the presence

537 of at least three loci (Bracamonte et al. 2015; Bracamonte 2013). Because next generation

538 sequencing is thought to generally overestimate the number of MHC alleles detected (Babik et

539 al. 2009; Lighten et al. 2014; Sommer et al. 2013), we took multiple precautions to avoid

540 artifacts (reconditioning steps, reduced numbers of PCR cycles, duplicates). Despite such

541 precautions and sequence confirmation using cloning (performed in (Bracamonte et al. 2015)),

542 we cannot exclude that some variants were called alleles even though artifactual (Sommer et

543 al. 2013). Again, as mtDNA sequencing revealed a large number of haplotypes ( $N=102)$, the

544 large diversity at the MHC displayed in this species may not be surprising.

545 Generally, our results are suggestive of a pattern of selective sweep at the MHC between the

546 two generations examined here. We found "silver eels" to exhibit lower mean number of alleles

547 and lower mean nucleotide distance than "glass eels", suggesting that the "silver eel"

548 generation was under a selective pressure that reduced its pool of MHC alleles to fewer and

549 more similar alleles. This observation suggests that either the selective pressure was

550 widespread amongst continental locations or that it acted when all eels experienced similar

551 conditions, as for instance, during the fastening spawning migration. A hypothetical selective

552 pressure imposed by $A$. crassus meets both criteria. Not only is this parasite ubiquitous in 
553 European freshwater systems (Wielgoss et al. 2008a) but it also impairs the swimming 554 performance of infected eels (Palstra et al. 2007).

555 Overall, the higher genetic diversity of "glass eels" together with the identification of two short 556 gene conversions in this study suggest an ongoing regeneration of the species immune adaptive 557 potential. Indeed gene conversation is a mechanism capable of generating novel diversity 558 within the $\mathrm{MHC}$ region, and seems to be a predominant mechanism in genetically depauperate 559 populations (Spurgin et al. 2011).

\section{Contemporary loss of MHC diversity: evidence of selection?}

561 The parasite $A$. crassus was presumably introduced in the European freshwater systems at the 562 beginning of the 1980s (Taraschewski et al. 1987), quickly spreading across continental water 563 bodies. The European eel is particularly susceptible to $A$. crassus infection (Knopf 2006) and

564 therefore its introduction provides an excellent biological calibration to evaluate its impact on

565 the evolution of diversity of the MHC. More specifically, we expected a signature of selection by 566 the parasite to be reflected in positively selected sites of the MHC variants. In total, we 567 detected 27 sites to be under or that have experienced positive selection along their 568 evolutionary history.

569 Bayesian skyline plots showed a steep decline in MHC genetic diversity as time approaches 570 present. This pattern is visible independently of the substitution rates and is reproducible with 571 independent runs, i.e. overlap of the probability density distributions of the posterior, skyline 572 and likelihood. Together, this suggests a real pattern and not an artifact. This decline in genetic 573 diversity of the adaptive gene is similar to those detected in genealogies exposed to events of 
574 episodic positive selection (Bedford et al. 2011), but also in functional regions involved in 575 adaptive responses (Padhi \& Verghese 2008). Two main factors may explain it. Firstly, it can be 576 attributed to the long terminal branching typical of phylogenies of genes evolving under 577 balancing selection (Richman 2000), amongst which the MHC is a classic example (Klein et al. 578 2007). MHC class II genes are also classical examples of genes evolving through recombination 579 (Reusch \& Langefors 2005) and gene conversion (Spurgin et al. 2011) - two mechanisms that 580 together with a relatively high copy number variation generates rapid genetic novelty (Chain et al. 2014). Therefore, a null expectation for balancing selection and generation of rapid genetic diversity - as predicted for MHC - would rather be that of either an expanding or stable population, which was not what we observed here.

Conversely, it can be attributed to an event of selection speculatively associated with the spread of $A$. crassus across the European freshwater systems. $A$. crassus was unknown to $A$. anguilla before its recent introduction, however it is naturally present in the $A$. japonica population (Wielgoss et al. 2008a). Hence, the frequency of the MHC alleles, or group of functionally similar MHC alleles, that confer resistance against this parasite would either be low or even absent in the European eel population (Eizaguirre et al. 2012b). The selection for those rare variants could have triggered the major loss of diversity we observed in the Bayesian plots and confirmed by the lower diversity indices of the "silver eels". Interestingly, the allelic lineage diversity of the MHC showed a constant increase with a particular acceleration approaching the contemporary period, as indicated by the lineages-through-time-plots of both generations. While we are unable to provide a direct functional link between such diversification and our

595 observations of gene conversion and recombination within this specific $\mathrm{MHC}$ region, these 
596 mechanisms have been associated with signatures of recovery after a genetic bottleneck in 597 genes under balancing selection (Richman 2000). Therefore, the inferred recent steep decline 598 followed by a very recent burst of lineage diversification upholds the occurrence of a selective 599 sweep in the MHC genealogy that pre-dated both our sampling points, as suggested by the 600 comparison between "silver eels" and "glass eels", with an ongoing recovery of the MHC 601 diversity.

602 From our results we can hypothesize two scenarios. A first scenario involves a link between a 603 sudden reduction in population size, a loss of genetic diversity and a constant selective pressure 604 extending after the bottleneck. In this scenario, genetic drift would affect overall genetic 605 diversity but since selection would continue to act, genetic diversity of positively selected 606 regions would remain low (Eimes et al. 2011). A second scenario relates to multiple MHC loci 607 carrying similar alleles due to recent duplications and to the hypothesis that a population would 608 experience a size reduction and an event of selection within the same time frame. In this scenario, the selective pressure through the bottleneck would lead to a faster fixation of 610 resistant alleles (Eimes et al. 2011).

\section{Limits of the study}

612 Evaluating demography in the European eel is complex particularly due to the difficulty of 613 sampling them at their mating ground and the reliance on indirect genetic evidence. Even 614 though patterns of selection and recent recovery of the MHC diversity seem robust, due to the 615 high allelic variation reported in this gene, we acknowledge that other coalescence models 616 could revealed refined patterns (Árnason \& Halldórsdóttir 2015; Wakeley 2013). It is indeed 
617 possible that multiple loci analysed together as one locus - although with same functional basis

618 - could create a pattern similar to multiple coalescence. To the best of our knowledge, multiple

619 merger models such as those described by Árnason and Halldórsdóttir (Árnason \&

620 Halldórsdóttir 2015) have not yet been applied to investigate the evolutionary signature that

621 linked copies of the same (functional) gene produce on the evaluation of genetic diversity and

622 demography. This thus limits working hypotheses and would be difficult to interpret.

623 Nonetheless, while further investigations are obviously needed to clarify fluctuations in genetic

624 diversity in such a complex but evolutionary relevant immune gene, we argue that our work

625 represents a first empirical step along this line of research.

\section{Conclusions}

627 In summary, our work reveals signatures of recent reduction in MHC genetic diversity and

628 suggests signs of ongoing recovery of this gene's diversity contributing to the immunogenetic 629 adaptive potential of this endangered species (Radwan et al. 2010; Sommer 2005; Stiebens et 630 al. 2013b). Future research will be needed to provide conclusive evidence as to which scenario 631 holds, accommodating also newer theories to further verify the validity of our findings. A future 632 perspective would be to extend the time-series analyses by incorporating screening of $\mathrm{MHC}$ 633 diversity in ongoing monitoring practices. This would be a valuable approach to access the 634 evolution of the species adaptive potential. 


\section{Acknowledgments}

637 The authors wish to thank J. Duhart, K. Bodles, D. Evans, E. Prigge and L. Marohn for eel

638 samples; J. Klein, L. Listmann, J. Nickel and M. Hoffmann for assistance with laboratory work; M.

639 Heckwolf and P. Roedler for help in processing glass eel samples; R. Scott for help designing the

640 maps.

641

642

643

644

645

646

647

648

649 References 
650

651

652

653

654

655

656

657

658

659

660

661

662

663

664

665

666

667

668

669

670

671

672

673

674

675

676

677

678

679

680

681

682

683

684

685

686

687

688

689

690

691

692

693

694

695

696

Allendorf FW, England PR, Luikart G, Ritchie PA, and Ryman N. 2008. Genetic effects of harvest on wild animal populations. Trends in Ecology \& Evolution 23:327-337.

Als TD, Hansen MM, Maes GE, Castonguay M, Riemann L, Aarestrup K, Munk P, Sparholt H, Hanel R, and Bernatchez L. 2011. All roads lead to home: panmixia of European eel in the Sargasso Sea. Molecular Ecology 20:1333-1346.

Apanius V, Penn D, Slev PR, Ruff LR, and Potts WK. 1997. The nature of selection on the major histocompatibility complex. Critical Reviews in Immunology 17.

Árnason E, and Halldórsdóttir K. 2015. Nucleotide variation and balancing selection at the Ckma gene in Atlantic cod: analysis with multiple merger coalescent models. PeerJ 3:e786.

Babik W, Taberlet P, Ejsmond MJ, and Radwan J. 2009. New generation sequencers as a tool for genotyping of highly polymorphic multilocus MHC system. Molecular Ecology Resources 9:713719.

Baltazar-Soares M, Biastoch A, Harrod C, Hanel R, Marohn L, Prigge E, Evans D, Bodles K, Behrens E, Böning Claus W, and Eizaguirre C. 2014. Recruitment Collapse and Population Structure of the European Eel Shaped by Local Ocean Current Dynamics. Current biology : CB 24:104-108.

Bedford T, Cobey S, and Pascual M. 2011. Strength and tempo of selection revealed in viral gene genealogies. BMC evolutionary biology 11:220.

Belkir K BP, Goudet J, Chikhi L, Bonhomme F. 1999. Genetix, logiciel sous Windows TM pour la genetique des populations. In: Laboratoire Genome et Populations UdM, editor. France.

Betran E, Rozas J, Navarro A, and Barbadilla A. 1997. The estimation of the number and the length distribution of gene conversion tracts from population DNA sequence data. Genetics 146:89-99.

Bonhommeau S, Chassot E, and Rivot E. 2008. Fluctuations in European eel (Anguilla anguilla) recruitment resulting from environmental changes in the Sargasso Sea. Fisheries Oceanography 17:32-44.

Bracamonte S, Baltazar-Soares M, and Eizaguirre C. 2015. Characterization of MHC class II genes in the critically endangered European eel (Anguilla anguilla). Conservation Genetics Resources:1-12.

Bracamonte SE. 2013. Characterization and evolution of MHC II genes in the European eel (Anguilla anguilla). Christian-Albrechts-Universität Kiel.

Chain FJ, Feulner PG, Panchal M, Eizaguirre C, Samonte IE, Kalbe M, Lenz TL, Stoll M, Bornberg-Bauer E, and Milinski M. 2014. Extensive copy-number variation of young genes across stickleback populations. PLoS genetics 10:e1004830.

Clarke KR. 1993. Non-parametric multivariate analyses of changes in community structure. Australian Journal of Ecology:117-143.

Cornuet JM, and Luikart G. 1996. Description and power analysis of two tests for detecting recent population bottlenecks from allele frequency data. Genetics 144:2001-2014.

Dannewitz J, Maes GE, Johansson L, Wickström H, Volckaert FAM, and Järvi T. 2005. Panmixia in the European eel: a matter of time. Proceedings of the Royal Society B: Biological Sciences 272:11291137.

Darriba D, Taboada GL, Doallo R, and Posada D. 2012. jModelTest 2: more models, new heuristics and parallel computing. Nature Methods 9:772-772.

Dekker W. 2003. Did lack of spawners cause the collapse of the European eel, Anguilla anguilla? Fisheries Management and Ecology 10:365-376.

Delport W, Poon AF, Frost SD, and Pond SLK. 2010. Datamonkey 2010: a suite of phylogenetic analysis tools for evolutionary biology. Bioinformatics 26:2455-2457.

Do C, Waples RS, Peel D, Macbeth G, Tillett BJ, and Ovenden JR. 2014. NeEstimator v2: reimplementation of software for the estimation of contemporary effective population size $(\mathrm{Ne})$ from genetic data. Molecular Ecology Resources 14:209-214. 
697

698

699

700

701

702

703

704

705

706

707

708

709

710

711

712

713

714

715

716

717

718

719

720

721

722

723

724

725

726

727

728

729

730

731

732

733

734

735

736

737

738

739

740

741

742

743

Drummond AJ, and Rambaut A. 2007. BEAST: Bayesian evolutionary analysis by sampling trees. BMC evolutionary biology 7:214.

Drummond AJ, Rambaut A, Shapiro B, and Pybus OG. 2005. Bayesian coalescent inference of past population dynamics from molecular sequences. Molecular Biology and Evolution 22:1185-1192.

Du M, Chen S-I, Liu Y-h, Liu Y, and Yang J-f. 2011. MHC polymorphism and disease resistance to vibrio anguillarum in 8 families of half-smooth tongue sole (Cynoglossus semilaevis). BMC Genetics $12: 78$.

EIFAAC/ICES. 2011. Country reports WGEEL 2011. Report on the eel stock and fisheries.

EIFAAC/ICES. 2013. Country reports WGEEL 2013. Report on the eel stock and fisheries.

Eimes J, Bollmer J, Whittingham L, Johnson J, Van Oosterhout C, and Dunn P. 2011. Rapid loss of MHC class II variation in a bottlenecked population is explained by drift and loss of copy number variation. Journal of Evolutionary Biology 24:1847-1856.

Eizaguirre C, and Baltazar-Soares M. 2014. Evolutionary Conservation-Evaluating the adaptive potential of species. Evolutionary Applications.

Eizaguirre C, Lenz TL, Kalbe M, and Milinski M. 2012a. Divergent selection on locally adapted major histocompatibility complex immune genes experimentally proven in the field. Ecology Letters 15:723-731.

Eizaguirre C, Lenz TL, Kalbe M, and Milinski M. 2012b. Rapid and adaptive evolution of MHC genes under parasite selection in experimental vertebrate populations. Nat Commun 3:621.

Eizaguirre C, Lenz TL, Sommerfeld RD, Harrod C, Kalbe M, and Milinski M. 2011. Parasite diversity, patterns of MHC II variation and olfactory based mate choice in diverging three-spined stickleback ecotypes. Evolutionary Ecology 25:605-622.

England PR, Luikart G, and Waples RS. 2010. Early detection of population fragmentation using linkage disequilibrium estimation of effective population size. Conservation genetics 11:2425-2430.

Excoffier L, and Lischer HEL. 2009. Arlequin suite ver 3.5: a new series of programs to perform population genetics analyses under Linux and Windows. Molecular Ecology Resources 10:564567.

Frankham R, Briscoe DA, and Ballou JD. 2002. Introduction to conservation genetics: Cambridge University Press.

Friedland KD, Miller MJ, and Knights B. 2007. Oceanic changes in the Sargasso Sea and declines in recruitment of the European eel. ICES Journal of Marine Science: Journal du Conseil 64:519-530.

Goudet J. 1995. FSTAT (version 1.2): a computer program to calculate F-statistics. Journal of Heredity 86:485-486.

Guindon S, and Gascuel O. 2003. A simple, fast, and accurate algorithm to estimate large phylogenies by maximum likelihood. Systematic biology 52:696-704.

Harrod C, Grey J, McCarthy T, and Morrissey M. 2005. Stable isotope analyses provide new insights into ecological plasticity in a mixohaline population of European eel. Oecologia 144:673-683.

Hendry AP, Kinnison MT, Heino M, Day T, Smith TB, Fitt G, Bergstrom CT, Oakeshott J, Jørgensen PS, Zalucki MP, Gilchrist G, Southerton S, Sih A, Strauss S, Denison RF, and Carroll SP. 2011.

Evolutionary principles and their practical application. Evolutionary Applications 4:159-183.

Hood GM. 2010. PopTools version 3.2.5 Available on the internet.

Hudson RR, and Kaplan NL. 1985. Statistical properties of the number of recombination events in the history of a sample of DNA sequences. Genetics 111:147-164.

ICES. 2015. ICES WKEELCITES REPORT 2015. Report on the eel stock and fisheries.

Jacobsen M, Pujolar JM, Gilbert MTP, Moreno-Mayar J, Bernatchez L, Als TD, Lobon-Cervia J, and Hansen MM. 2014. Speciation and demographic history of Atlantic eels (Anguilla anguilla and $A$. rostrata) revealed by mitogenome sequencing. Heredity 113:432-442. 
744

Janeway CA, Travers P, Walport M, and Shlomchik MJ. 2005. Immunobiology: the immune system in health and disease.

Kalinowski ST. 2005. hp-rare 1.0: a computer program for performing rarefaction on measures of allelic richness. Molecular Ecology Notes 5:187-189.

Keith DA, Akçakaya HR, Thuiller W, Midgley GF, Pearson RG, Phillips SJ, Regan HM, Araujo MB, and Rebelo TG. 2008. Predicting extinction risks under climate change: coupling stochastic population models with dynamic bioclimatic habitat models. Biology Letters 4:560-563.

Kettle AJ, Bakker DCE, and Haines K. 2008a. Impact of the North Atlantic Oscillation on the trans-Atlantic migrations of the European eel (Anguilla anguilla). J Geophys Res 113:G03004.

Kettle AJ, Bakker DCE, and Haines K. 2008b. Impact of the North Atlantic Oscillation on the trans-Atlantic migrations of the European eel (Anguilla anguilla). Journal of Geophysical ResearchBiogeosciences 113:26.

Kimura M, and Ohta T. 1978. Stepwise mutation model and distribution of allelic frequencies in a finite population. Proceedings of the National Academy of Sciences 75:2868-2872.

Kingman JFC. 1982. The coalescent. Stochastic processes and their applications 13:235-248.

Kirk RS. 2003. The impact of Anguillicola crassus on European eels. Fisheries Management and Ecology 10:385-394.

Klein J, Sato A, and Nikolaidis N. 2007. MHC, TSP, and the origin of species: from immunogenetics to evolutionary genetics. Annu Rev Genet 41:281-304.

Knopf K. 2006. The swimbladder nematode Anguillicola crassus in the European eel Anguilla anguilla and the Japanese eel Anguilla japonica: differences in susceptibility and immunity between a recently colonized host and the original host. Journal of Helminthology 80:129-136.

Lenz TL, and Becker S. 2008. Simple approach to reduce PCR artefact formation leads to reliable genotyping of $\mathrm{MHC}$ and other highly polymorphic loci. Implications for evolutionary analysis. Gene 427:117-123.

Lenz TL, Eizaguirre C, Kalbe M, and Milinski M. 2013. Evaluating patterns of convergent evolution and trans-species polymorphism at MHC immunogenes in two sympatric stickleback species Evolution 67:2400-2412.

Librado P, and Rozas J. 2009. DnaSP v5: a software for comprehensive analysis of DNA polymorphism data. Bioinformatics 25:1451-1452.

Lighten J, Oosterhout C, and Bentzen P. 2014. Critical review of NGS analyses for de novo genotyping multigene families. Molecular Ecology.

Luikart G, Allendorf F, Cornuet J, and Sherwin W. 1998. Distortion of allele frequency distributions provides a test for recent population bottlenecks. Journal of Heredity 89:238-247.

Maes G, and Volckaert F. 2002. Clinal genetic variation and isolation by distance in the European eel Anguilla anguilla (L.). Biological Journal of the Linnean Society 77:509-521.

McCallum H. 2008. Tasmanian devil facial tumour disease: lessons for conservation biology. Trends in Ecology \& Evolution 23:631-637.

McMahon BJ, Teeling EC, and Höglund J. 2014. How and why should we implement genomics into conservation? Evolutionary Applications.

Miller MJ. 2009. Ecology of anguilliform leptocephali: remarkable transparent fish larvae of the ocean surface layer. Aqua-BioSci Monogr 2.

Munk P, Hansen MM, Maes GE, Nielsen TG, Castonguay M, Riemann L, Sparholt H, Als TD, Aarestrup K, Andersen NG, and Bachler M. 2010. Oceanic fronts in the Sargasso Sea control the early life and drift of Atlantic eels. Proceedings of the Royal Society B: Biological Sciences 277:3593-3599.

Murrell B, Wertheim JO, Moola S, Weighill T, Scheffler K, and Kosakovsky Pond SL. 2012. Detecting Individual Sites Subject to Episodic Diversifying Selection. PLoS Genet 8:e1002764. 
791

792

793

794

795

796

797

798

799

800

801

802

803

804

805

806

807

808

809

810

811

812

813

814

815

816

817

818

819

820

821

822

823

824

825

826

827

828

829

830

831

832

833

834

835

836

Narum SR. 2006. Beyond Bonferroni: less conservative analyses for conservation genetics. Conservation genetics 7:783-787.

Nee S, Mooers AO, and Harvey PH. 1992. Tempo and mode of evolution revealed from molecular phylogenies. Proceedings of the National Academy of Sciences 89:8322-8326.

Padhi A, and Verghese B. 2008. Positive natural selection in the evolution of human metapneumovirus attachment glycoprotein. Virus research 131:121-131.

Palstra AP, Heppener DFM, van Ginneken VJT, Székely C, and van den Thillart GEEJM. 2007. Swimming performance of silver eels is severely impaired by the swim-bladder parasite Anguillicola crassus. Journal of Experimental Marine Biology and Ecology 352:244-256.

Piertney S, and Oliver M. 2006. The evolutionary ecology of the major histocompatibility complex. Heredity 96:7-21.

Pond SLK, and Frost SD. 2005. Datamonkey: rapid detection of selective pressure on individual sites of codon alignments. Bioinformatics 21:2531-2533.

Prigge E, Marohn L, Oeberst R, and Hanel R. 2013. Model prediction vs. reality-testing the predictions of a European eel (Anguilla anguilla) stock dynamics model against the in situ observation of silver eel escapement in compliance with the European eel regulation. ICES Journal of Marine Science: Journal du Conseil 70:309-318.

Pritchard JK, Stephens M, and Donnelly P. 2000. Inference of population structure using multilocus genotype data. Genetics 155:945-959.

Pujolar J, Bevacqua D, Capoccioni F, Ciccotti E, De Leo G, and Zane L. 2011. No apparent genetic bottleneck in the demographically declining European eel using molecular genetics and forwardtime simulations. Conservation genetics 12:813-825.

Pujolar JM, Jacobsen M, Als TD, Frydenberg J, Munch K, Jonsson B, Jian JB, Cheng L, Maes GE, and Bernatchez L. 2014. Genome-wide single-generation signatures of local selection in the panmictic European eel. Molecular Ecology 23:2514-2528.

Pujolar JM, Jacobsen M, Frydenberg J, Als TD, Larsen PF, Maes G, Zane L, Jian J, Cheng L, and Hansen MM. 2013. A resource of genome-wide single-nucleotide polymorphisms generated by RAD tag sequencing in the critically endangered European eel. Molecular Ecology Resources 13:706-714.

Pujolar JM, Maes GE, Van Houdt JKJ, and Zane L. 2009. Isolation and characterization of expressed sequence tag-linked microsatellite loci for the European eel (Anguilla anguilla). Molecular Ecology Resources 9:233-235.

Radwan J, Biedrzycka A, and Babik W. 2010. Does reduced MHC diversity decrease viability of vertebrate populations? Biological Conservation 143:537-544.

Reche PA, and Reinherz EL. 2003. Sequence variability analysis of human class I and class II MHC molecules: functional and structural correlates of amino acid polymorphisms. Journal of molecular biology 331:623-641.

Reusch TB, and Langefors A. 2005. Inter-and intralocus recombination drive MHC class IIB gene diversification in a teleost, the three-spined stickleback Gasterosteus aculeatus. Journal of Molecular Evolution 61:531-541.

Richman A. 2000. Evolution of balanced genetic polymorphism. Molecular Ecology 9:1953-1963.

Robinet T, and Feunteun E. 2002. Sublethal Effects of Exposure to Chemical Compounds: A Cause for the Decline in Atlantic Eels? Ecotoxicology 11:265-277.

Rogers AR, and Harpending H. 1992. Population growth makes waves in the distribution of pairwise genetic differences. Molecular Biology and Evolution 9:552-569.

Sommer S. 2005. The importance of immune gene variability (MHC) in evolutionary ecology and conservation. Front Zool 2:16. 
837

838

839

840

841

842

843

844

845

846

847

848

849

850

851

852

853

854

855

856

857

858

859

860

861

862

863

864

865

866

867

868

869

870

871

872

873

874

875

876

877

878

879

880

881

882

883

Sommer S, Courtiol A, and Mazzoni CJ. 2013. MHC genotyping of non-model organisms using nextgeneration sequencing: a new methodology to deal with artefacts and allelic dropout. $B M C$ genomics 14:542.

Spielman D, Brook BW, and Frankham R. 2004. Most species are not driven to extinction before genetic factors impact them. Proceedings of the National Academy of Sciences of the United States of America 101:15261-15264.

Spurgin LG, and Richardson DS. 2012. How pathogens drive genetic diversity: MHC, mechanisms and misunderstandings. Proceedings of the Royal Society B: Biological Sciences 277:979-988.

Spurgin LG, van Oosterhout C, Illera JC, Bridgett S, Gharbi K, Emerson BC, and Richardson DS. 2011. Gene conversion rapidly generates major histocompatibility complex diversity in recently founded bird populations. Molecular Ecology 20:5213-5225.

Stiebens VA, Merino SE, Chain FJ, and Eizaguirre C. 2013a. Evolution of MHC class I genes in the endangered loggerhead sea turtle (Caretta caretta) revealed by 454 amplicon sequencing. BMC evolutionary biology 13:95.

Stiebens VA, Merino SE, Roder C, Chain FJJ, Lee PLM, and Eizaguirre C. 2013b. Living on the edge: how philopatry maintains adaptive potential. Proceedings of the Royal Society B: Biological Sciences 280.

Sutton JT, Nakagawa S, Robertson BC, and Jamieson IG. 2011. Disentangling the roles of natural selection and genetic drift in shaping variation at MHC immunity genes. Molecular Ecology 20:4408-4420.

Sutton JT, Robertson BC, and Jamieson IG. 2015. MHC variation reflects the bottleneck histories of New Zealand passerines. Molecular Ecology 24:362-373.

Tajima F. 1989. Statistical method for testing the neutral mutation hypothesis by DNA polymorphism. Genetics 123:585-595.

Tamura K, Peterson D, Peterson N, Stecher G, Nei M, and Kumar S. 2011. MEGA5: molecular evolutionary genetics analysis using maximum likelihood, evolutionary distance, and maximum parsimony methods. Molecular Biology and Evolution 28:2731-2739.

Taraschewski H, Moravec F, Lamah T, and Anders K. 1987. Distribution and morphology of two helminths recently introduced into European eel populations: Anguillicola crassus (Nematoda, Dracunculoidea) and Paratenuisentis ambiguus (Acanthocephala, Tenuisentidae). Diseases of Aquatic Organisms 3:167-176.

Tesch F. 2003. The Eel. Oxford: Blackwell Sciences Ltd.

Thomas CD, Cameron A, Green RE, Bakkenes M, Beaumont L, Collingham YC, Erasmus BFN, de Siqueira MF, Grainger A, Hannah L, Hughes L, Huntley B, van Jaarsveld AS, Midgley GF, Miles L, OrtegaHuerta MA, Townsend Peterson A, Phillips OL, and Williams SE. 2004. Extinction risk from climate change. Nature 427:145-148.

Van Ginneken V, Ballieux B, Willemze R, Coldenhoff K, Lentjes E, Antonissen E, Haenen O, and van den Thillart G. 2005. Hematology patterns of migrating European eels and the role of EVEX virus. Comparative Biochemistry and Physiology Part C: Toxicology \& Pharmacology 140:97-102.

Wakeley J. 2013. Coalescent theory has many new branches. Theoretical Population Biology 87:1-4.

Waples RS, and Do C. 2010. Linkage disequilibrium estimates of contemporary Ne using highly variable genetic markers: a largely untapped resource for applied conservation and evolution. Evolutionary Applications 3:244-262.

Waples RS, and Do CHI. 2008. Idne: a program for estimating effective population size from data on linkage disequilibrium. Molecular Ecology Resources 8:753-756.

Weir BS. 1990. Genetic data analysis. Methods for discrete population genetic data: Sinauer Associates, Inc. Publishers. 
884 Wielgoss S, Taraschewski H, Meyer A, and Wirth T. 2008a. Population structure of the parasitic

885

886

887

888

889

890

891

892

893

894

895

896

897

898 nematode Anguillicola crassus, an invader of declining North Atlantic eel stocks. Molecular Ecology 17:3478-3495.

Wielgoss S, Wirth T, and Meyer A. 2008b. Isolation and characterization of 12 dinucleotide microsatellites in the European eel, Anguilla anguilla L., and tests of amplification in other species of eels. Molecular Ecology Resources 8:1382-1385.

Wirth T, and Bernatchez L. 2001. Genetic evidence against panmixia in the European eel. Nature 409:1037-1040.

Wirth T, and Bernatchez L. 2003. Decline of North Atlantic eels: a fatal synergy? Proceedings of the Royal Society of London Series B: Biological Sciences 270:681-688.

Yang Z. 2007. PAML 4: phylogenetic analysis by maximum likelihood. Molecular Biology and Evolution 24:1586-1591.

Yang Z, Wong WS, and Nielsen R. 2005. Bayes empirical Bayes inference of amino acid sites under positive selection. Molecular Biology and Evolution 22:1107-1118. 


\section{Table $\mathbf{1}$ (on next page)}

GPS coordinates and summary statistics for each sampling location

The G_prefix stands for "glass eels". AD2010, AD2011 and AD2012 refer to the three cohorts captured in Adour, France, in the years of 2010, 2011 and 2012 respectively. The glass eels of BU (Burrishole, (UK), BNIRL (Bann, Nothern Ireland), VSWE (Viskan, Sweden), TENG (Tees, England), EGER (Erms, Germany), OSPA (Oria, Spain), VFRA (Villaine, France), WENG (Wye, England), TITA (Tuscany, Italy), and NIRL (Carlingford, Northern Ireland) were all captured in 2009. All other samples relate to "silver eels". The remaining acronyms have the following meaning: LC (Larne Lagoon), BT (Bann Toome), Q (Quoile), BU (Burrishole), BL (BannLower), SLC (LoughComber), DK (Denmark), LL (LarneLagoon), SLB (Boretree), GL (Glynn Lagoon), Fl (Finland), PT (Portugal), Ger (Germany). N (Number of samples) and respective summary statistics for each location is also shown: nHap (number of haplotypes), S (segregation sites), $\mathrm{Hd}$ (Haplotype diversity), $\pi$ (nucleotide diversity), $\mathrm{He}$ (expected heterozygosity), Ho (observed heterozygosity), Ar (Rarefied allelic richness), Fis (Inbreeding coefficient). Values in brackets represent confidence intervals, with the exception of $\mathrm{He}$ and $\mathrm{Ho}$, which represents standard deviations $*=p<0,05 ;{ }^{* *}=p<0.001$. 


\begin{tabular}{|c|c|c|c|c|c|c|c|c|c|c|c|}
\hline Population & GPS coordinates & $\mathbf{n}$ & nHap & $s$ & $H d$ & $\pi$ & Tajima-D & $\mathrm{He}$ & Ho & Ar & FIS \\
\hline$\underset{\text { (France) }}{\text { G_AD2010 }}$ & & 155 & 31 & 30 & $\begin{array}{c}0.818 \\
(0.234-0.859)\end{array}$ & 0.00443 & $\begin{array}{c}-2.3905^{* *} \\
(-1.6033-1.9883)\end{array}$ & $\begin{array}{c}0.7343 \\
(0.2689)\end{array}$ & $\begin{array}{c}0.6177 \\
(0.2440)\end{array}$ & 2.9 & $\begin{array}{c}0.1593 \\
(0.1365-0.1760)\end{array}$ \\
\hline $\begin{array}{c}\text { G_AD2011 } \\
\text { (France) }\end{array}$ & $43^{\circ} 31^{\prime} 48^{\prime \prime N}$ N. $1^{\circ} 31^{\prime} 28^{\prime \prime} \mathrm{W}$ & 129 & 35 & 32 & $\begin{array}{c}0.862 \\
(0.2965-0.8641)\end{array}$ & 0.00514 & $\begin{array}{c}-2.0896^{*} \\
(-1.6068-2.1393)\end{array}$ & $\begin{array}{c}0.7472 \\
(0.2550)\end{array}$ & $\begin{array}{c}0.6243 \\
(0.2378)\end{array}$ & 2.94 & $\begin{array}{c}0.1650 \\
(0.1375-0.1838)\end{array}$ \\
\hline $\begin{array}{c}\text { G_AD2012 } \\
\text { (France) }\end{array}$ & & 121 & 34 & 35 & $\begin{array}{c}0.851 \\
(0.2401-0.8568)\end{array}$ & 0.00516 & $\begin{array}{c}-2.1804^{* *} \\
(-1.5977-2.0335)\end{array}$ & $\begin{array}{c}0.7480 \\
(0.2488)\end{array}$ & $\begin{array}{c}0.6245 \\
(0.2344)\end{array}$ & 2.94 & $\begin{array}{c}0.1658 \\
(0.1398-0.1831)\end{array}$ \\
\hline $\begin{array}{c}\mathrm{LC} \\
\text { (Ireland) }\end{array}$ & $54^{\circ} 50^{\prime} 54^{\prime \prime N}$. 548'51"W & 19 & 4 & 5 & $\begin{array}{c}0.7135 \\
(0.1053-0.8714)\end{array}$ & 0.00482 & $\begin{array}{c}-0.6022 \\
(-1.7188-1.8481)\end{array}$ & $\begin{array}{c}0.7356 \\
(0.2725)\end{array}$ & $\begin{array}{c}0.5769 \\
(0.2695)\end{array}$ & 2.91 & $\begin{array}{c}0.2180 \\
(0.1319-0.2482)\end{array}$ \\
\hline $\begin{array}{c}\text { BT } \\
\text { (Ireland) }\end{array}$ & $54^{\circ} 45^{\prime} 23^{\prime \prime N}$. $6^{\circ} 27^{\prime} 48^{\prime \prime} \mathrm{W}$ & 17 & 9 & 11 & $\begin{array}{c}0.8456 \\
(0.3235-0.9044)\end{array}$ & 0.0069 & $\begin{array}{c}-0.9266 \\
(-1.7987-1.9496)\end{array}$ & $\begin{array}{c}0.7314 \\
(0.2624)\end{array}$ & $\begin{array}{c}0.6528 \\
(0.2695)\end{array}$ & 2.88 & $\begin{array}{c}0.1106 \\
(0.0251-0.1243)\end{array}$ \\
\hline $\begin{array}{c}Q \\
\text { (Ireland) }\end{array}$ & $54^{\circ} 22^{\prime} 0^{\prime \prime N}$. $5^{\circ} 40^{\prime} 4^{\prime \prime} \mathrm{W}$ & 15 & 5 & 6 & $\begin{array}{c}0.6381 \\
(0.1333-0.8667)\end{array}$ & 0.0043 & $\begin{array}{c}-0.6099 \\
(-1.8159-1.7688)\end{array}$ & $\begin{array}{c}0.7315 \\
(0.2504)\end{array}$ & $\begin{array}{c}0.5521 \\
(0.2693)\end{array}$ & 2.87 & $\begin{array}{c}0.2537 \\
(0.1427-0.2716)\end{array}$ \\
\hline $\begin{array}{c}\text { BU } \\
\text { (N.Ireland) }\end{array}$ & $53^{\circ} 55^{\prime} 4^{\prime \prime}$ N. 9³4'20"W & 16 & 4 & 7 & $\begin{array}{c}0.575 \\
(0.1250-0.8833)\end{array}$ & 0.0048 & $\begin{array}{c}-0.6099 \\
(-1.6965-1.8617)\end{array}$ & $\begin{array}{c}0.7477 \\
(0.2662)\end{array}$ & $\begin{array}{c}0.6367 \\
(0.2537)\end{array}$ & 2.95 & $\begin{array}{c}0.1527 \\
(0.0546-0.1761)\end{array}$ \\
\hline $\begin{array}{c}\mathrm{BL} \\
\text { (Ireland) }\end{array}$ & $55^{\circ} 9^{\prime} 15^{\prime \prime N}$. 6 $42^{\prime} 5^{\prime \prime} \mathrm{W}$ & 11 & 5 & 5 & $\begin{array}{c}0.8364 \\
(0.1818-0.9091)\end{array}$ & 0.00524 & $\begin{array}{c}-0.6099 \\
(-1.7116-1.8376)\end{array}$ & $\begin{array}{c}0.7060 \\
(0.3007)\end{array}$ & $\begin{array}{c}0.6152 \\
(0.2611)\end{array}$ & 2.82 & $\begin{array}{c}0.1350 \\
(-0.0315-0.1674)\end{array}$ \\
\hline $\begin{array}{c}\text { SLC } \\
\text { (Ireland) }\end{array}$ & $54^{\circ} 32^{\prime} 20^{\prime \prime N} 5^{\circ} 42^{\prime} 6 " \mathrm{~W}$ & 9 & 7 & 7 & $\begin{array}{c}0.8056 \\
(0.2222-0.9167)\end{array}$ & 0.00612 & $\begin{array}{c}-0.7082 \\
(-1.6775-1.7558)\end{array}$ & $\begin{array}{c}0.7461 \\
(0.2605)\end{array}$ & $\begin{array}{c}0.6301 \\
(0.2936)\end{array}$ & 2.93 & $\begin{array}{c}0.1606 \\
(-0.0584-0.1802)\end{array}$ \\
\hline $\begin{array}{c}\text { DK } \\
\text { (Denmark) }\end{array}$ & $57^{\circ} 29^{\prime} \mathrm{N} .10^{\circ} 36^{\prime} \mathrm{E}$ & 19 & 13 & 16 & $\begin{array}{c}0.9474 \\
(0.2924-0.9006)\end{array}$ & 0.00703 & $\begin{array}{c}-1.6199 \\
(-1.8612-1.9447)\end{array}$ & $\begin{array}{c}0.7547 \\
(0.2183)\end{array}$ & $\begin{array}{c}0.6658 \\
(0.2193)\end{array}$ & 2.93 & $\begin{array}{c}0.1208 \\
(0.0347-0.1432)\end{array}$ \\
\hline $\begin{array}{c}\mathrm{LL} \\
\text { (Ireland) }\end{array}$ & $54^{\circ} 49^{\prime} 26^{\prime \prime N}$. $5^{\circ} 47^{\prime} 40^{\prime \prime} \mathrm{W}$ & 13 & 7 & 6 & $\begin{array}{c}0.8462 \\
(0.1539-0.9103)\end{array}$ & 0.00545 & $\begin{array}{c}-0.0199 \\
(-1.7276-1.7731)\end{array}$ & $\begin{array}{c}0.7169 \\
(0.2788)\end{array}$ & $\begin{array}{c}0.5865 \\
(0.2776)\end{array}$ & 2.83 & $\begin{array}{c}0.1884 \\
(0.0796-0.1975)\end{array}$ \\
\hline $\begin{array}{c}\text { SLB } \\
\text { (Ireland) }\end{array}$ & $54^{\circ} 26^{\prime} 39^{\prime \prime N}$. $5^{\circ} 35^{\prime} 20^{\prime \prime} \mathrm{W}$ & 15 & 6 & 5 & $\begin{array}{c}0.8476 \\
(0.1333-0.8667)\end{array}$ & 0.00427 & $\begin{array}{c}-0.0723 \\
(-1.6850-1.8912)\end{array}$ & $\begin{array}{c}0.7462 \\
(0.2648)\end{array}$ & $\begin{array}{c}0.6025 \\
(0.2653)\end{array}$ & 2.94 & $\begin{array}{c}0.1989 \\
(0.0797-0.2264)\end{array}$ \\
\hline $\begin{array}{c}\mathrm{GL} \\
\text { (Ireland) }\end{array}$ & $54^{\circ} 49^{\prime} 55 N^{\circ} .5^{\circ} 48^{\prime} 40 \mathrm{~W}$ & 14 & 10 & 12 & $\begin{array}{c}0.9341 \\
(0.3846-0.9231)\end{array}$ & 0.00844 & $\begin{array}{c}-0.8279 \\
(-1.7574-1.8956)\end{array}$ & $\begin{array}{c}0.7548 \\
(0.2494)\end{array}$ & $\begin{array}{c}0.6549 \\
(0.2428)\end{array}$ & 2.96 & $\begin{array}{c}0.1377 \\
(0.0057-0.1587)\end{array}$ \\
\hline $\begin{array}{c}\mathrm{Fl} \\
\text { (FInland) }\end{array}$ & $60^{\circ} 26^{\prime} \mathrm{N} ; 26^{\circ} 57^{\prime} \mathrm{E}$ & 19 & 9 & 9 & $\begin{array}{c}0.883 \\
(0.2982-0.8947)\end{array}$ & 0.00661 & $\begin{array}{c}-0.3195 \\
(-1.6406-1.7888)\end{array}$ & $\begin{array}{c}0.735 \\
(0.2600)\end{array}$ & $\begin{array}{l}0.6348 \\
(0.2547)\end{array}$ & 2.89 & $\begin{array}{c}0.1397 \\
(0.0587-0.1621)\end{array}$ \\
\hline $\begin{array}{c}\text { PT } \\
\text { (Portugal) }\end{array}$ & $38^{\circ} 46^{\prime}$ N. $9^{\circ} 01^{\prime} \mathrm{W}$ & 17 & 7 & 8 & $\begin{array}{c}0.8309 \\
(0.2279-0.8971)\end{array}$ & 0.00644 & $\begin{array}{c}-0.1299 \\
(-1.7057-1.9351)\end{array}$ & $\begin{array}{c}0.7581 \\
(0.2414)\end{array}$ & $\begin{array}{c}0.6472 \\
(0.2387)\end{array}$ & 2.97 & $\begin{array}{c}0.1397 \\
(0.0180-0.1752)\end{array}$ \\
\hline
\end{tabular}




\begin{tabular}{|c|c|c|c|c|c|c|c|c|c|c|c|}
\hline $\begin{array}{c}\text { Ger } \\
\text { (Germany) }\end{array}$ & $54^{\circ} 17^{\prime} 16$ N. $10^{\circ} 14^{\prime} 54^{\prime \prime E}$ & 17 & 6 & 6 & $\begin{array}{c}0.7794 \\
(0.1177-0.8824)\end{array}$ & 0.00536 & $\begin{array}{c}0.2311 \\
(-1.7057-1.9718)\end{array}$ & $\begin{array}{c}0.7328 \\
(0.2516)\end{array}$ & $\begin{array}{c}0.6041 \\
(0.2586)\end{array}$ & 2.88 & $\begin{array}{c}0.1809 \\
(0.0779-0.2012)\end{array}$ \\
\hline $\begin{array}{c}\text { G_BU } \\
\text { (Nireland) }\end{array}$ & $53^{\circ} 55^{\prime} 4^{\prime \prime N}$ N. 9³4'20"W & 14 & 6 & 6 & $\begin{array}{c}0.78 \\
(0.1429-0.9011)\end{array}$ & 0.00494 & $\begin{array}{c}-0.26534 \\
(-1.6705-1.6921)\end{array}$ & $\begin{array}{c}0.7224 \\
(0.2741)\end{array}$ & $\begin{array}{l}0.6294 \\
(0.272)\end{array}$ & 2.85 & $\begin{array}{c}0.1332 \\
(0.0309-0.1508)\end{array}$ \\
\hline $\begin{array}{l}\text { G_BNIRL } \\
\text { (NIreland) }\end{array}$ & $55^{\circ} 9^{\prime} 15^{\prime \prime N}$. 6.42'5"W & 12 & 8 & 9 & $\begin{array}{c}0.909 \\
(0.3030-0.9242)\end{array}$ & 0.00629 & $\begin{array}{c}-1.02555 \\
(-1.7551-1.7575)\end{array}$ & $\begin{array}{c}0.7224 \\
(0.2741)\end{array}$ & $\begin{array}{c}0.6294 \\
(0.2720)\end{array}$ & 2.81 & $\begin{array}{c}0.1635 \\
(0.0209-0.2125)\end{array}$ \\
\hline $\begin{array}{l}\text { G_VSWE } \\
\text { (Sweden) }\end{array}$ & $57^{\circ} 13^{\prime} 30^{\prime \prime}$ N. $12^{\circ} 12^{\prime} 20^{\prime \prime} \mathrm{E}$ & 16 & 8 & 7 & $\begin{array}{c}0.00433 \\
(0.1250-0.8750)\end{array}$ & 0.00433 & $\begin{array}{c}-0.96247 \\
(-1.7280-1.9375)\end{array}$ & $\begin{array}{l}0.7432 \\
(0.2700)\end{array}$ & $\begin{array}{l}0.6335 \\
(0.2946)\end{array}$ & 2.93 & $\begin{array}{c}0.1518 \\
(0.0618-0.1637)\end{array}$ \\
\hline $\begin{array}{l}\text { G_TENG } \\
\text { (England) }\end{array}$ & $54^{\circ} 37^{\prime} 21^{\prime \prime}$ N. $1^{\circ} 9^{\prime} 23^{\prime \prime} \mathrm{W}$ & 10 & 7 & 7 & $\begin{array}{c}0.911 \\
(0.0000-0.9111)\end{array}$ & 0.00515 & $\begin{array}{c}-1.11638 \\
(-1.7118-1.6872)\end{array}$ & $\begin{array}{c}0.7402 \\
(0.2584)\end{array}$ & $\begin{array}{c}0.6591 \\
(0.2404)\end{array}$ & 2.9 & $\begin{array}{c}0.1160 \\
(-0.0810-0.1260)\end{array}$ \\
\hline $\begin{array}{c}\text { G_EGER } \\
\text { (Germany) }\end{array}$ & $48^{\circ} 35^{\prime} 35^{\prime \prime N}$ N. $9^{\circ} 14^{\prime} 11^{\prime \prime} \mathrm{E}$ & 5 & 4 & 3 & $\begin{array}{c}0.9 \\
(0.0000-0.9000)\end{array}$ & 0.00395 & $\begin{array}{c}-0.17475 \\
(-1.4554-1.6407)\end{array}$ & $\begin{array}{c}0.7111 \\
(0.2951)\end{array}$ & $\begin{array}{c}0.6000 \\
(0.3086)\end{array}$ & 2.82 & $\begin{array}{c}0.1724 \\
(-0.2152-0.1724)\end{array}$ \\
\hline $\begin{array}{l}\text { G_OSPA } \\
\text { (Spain) }\end{array}$ & $43^{\circ} 17^{\prime} 25^{\prime \prime}$ N. $2^{\circ} 7^{\prime} 55^{\prime \prime} \mathrm{W}$ & 4 & 3 & 2 & $\begin{array}{c}0.833 \\
(0.0000-1.0000)\end{array}$ & 0.00282 & $\begin{array}{c}-0.7099 \\
(-0.7968-2.0118)\end{array}$ & $\begin{array}{c}0.7265 \\
(0.2894)\end{array}$ & $\begin{array}{c}0.6705 \\
(0.3483)\end{array}$ & 2.85 & $\begin{array}{c}0.0876 \\
(-0.3333-0.0876)\end{array}$ \\
\hline $\begin{array}{l}\text { G_VFRA } \\
\text { (France) }\end{array}$ & $47^{\circ} 30^{\prime} 20^{\prime \prime}$ N. $2^{\circ} 29^{\prime} 57^{\prime \prime} \mathrm{W}$ & 3 & 2 & 2 & $\begin{array}{c}0.667 \\
(0.0000-1.0000)\end{array}$ & 0.00377 & - & $\begin{array}{c}0.7439 \\
(0.2442)\end{array}$ & $\begin{array}{c}0.6970 \\
(0.2800)\end{array}$ & 2.88 & $\begin{array}{c}0.0800 \\
(-1.0000-0.0800)\end{array}$ \\
\hline $\begin{array}{l}\text { G_WENG } \\
\text { (England) }\end{array}$ & $51^{\circ} 36^{\prime} 36^{\prime \prime}$ N. $2^{\circ} 39^{\prime} 43^{\prime \prime} W$ & 5 & 4 & 4 & $\begin{array}{c}0.9 \\
(0.0000-1.0000)\end{array}$ & 0.00565 & $\begin{array}{c}0.27345 \\
(-1.1743-1.6859)\end{array}$ & $\begin{array}{c}0.7323 \\
(0.2221)\end{array}$ & $\begin{array}{c}0.6455 \\
(0.2686)\end{array}$ & 2.83 & $\begin{array}{c}0.1315 \\
(-0.2840-0.1315)\end{array}$ \\
\hline $\begin{array}{l}\text { G_TITA } \\
\text { (Italy) }\end{array}$ & $43^{\circ} 40^{\prime} 47^{\prime \prime}$ N. $10^{\circ} 16^{\prime} 36^{\prime \prime} \mathrm{E}$ & 4 & 3 & 3 & $\begin{array}{c}0.833 \\
(0.0000-1.0000)\end{array}$ & 0.00471 & $\begin{array}{c}0.16766 \\
(-0.8173-2.0118)\end{array}$ & $\begin{array}{l}0.7175 \\
(0.3169)\end{array}$ & $\begin{array}{c}0.5568 \\
(0.3444)\end{array}$ & 2.85 & $\begin{array}{c}0.2519 \\
(-0.2609-0.2519)\end{array}$ \\
\hline $\begin{array}{c}\text { G_NIRL } \\
\text { (NIreland) }\end{array}$ & $54.07^{\circ} \mathrm{N} .6 .19^{\circ} \mathrm{W}$ & 3 & 3 & 3 & $\begin{array}{c}1 \\
(0.0000-1.0000)\end{array}$ & 0.00563 & - & $\begin{array}{l}0.6869 \\
(0.2787\end{array}$ & $\begin{array}{c}0.6636 \\
(0.3513)\end{array}$ & 2.71 & $\begin{array}{c}0.0379 \\
(-0.3398-0.0597)\end{array}$ \\
\hline
\end{tabular}




\section{Table 2 (on next page)}

Molecular indices of "silver eels" and "glass eels"

Summary statistics of neutral evolving markers calculated for the two distinct generations. $\mathrm{n}$ $=$ number of samples used; $\mathrm{nHap}=$ number of haplotypes; $\mathrm{S}=$ segregation sites; $\mathrm{Hd}=$ Haplotype diversity; $\pi=$ nucleotide diversity; $\mathrm{He}=$ expected heterozygosity; Ho observed heterozygosity; Ar = Rarefied allelic richness; Fis = Inbreeding coefficient; Values in brackets represent confidence intervals, with the exception of He and Ho which represents standard deviations $*=p<0,05 ; * *=p<0.001$ 


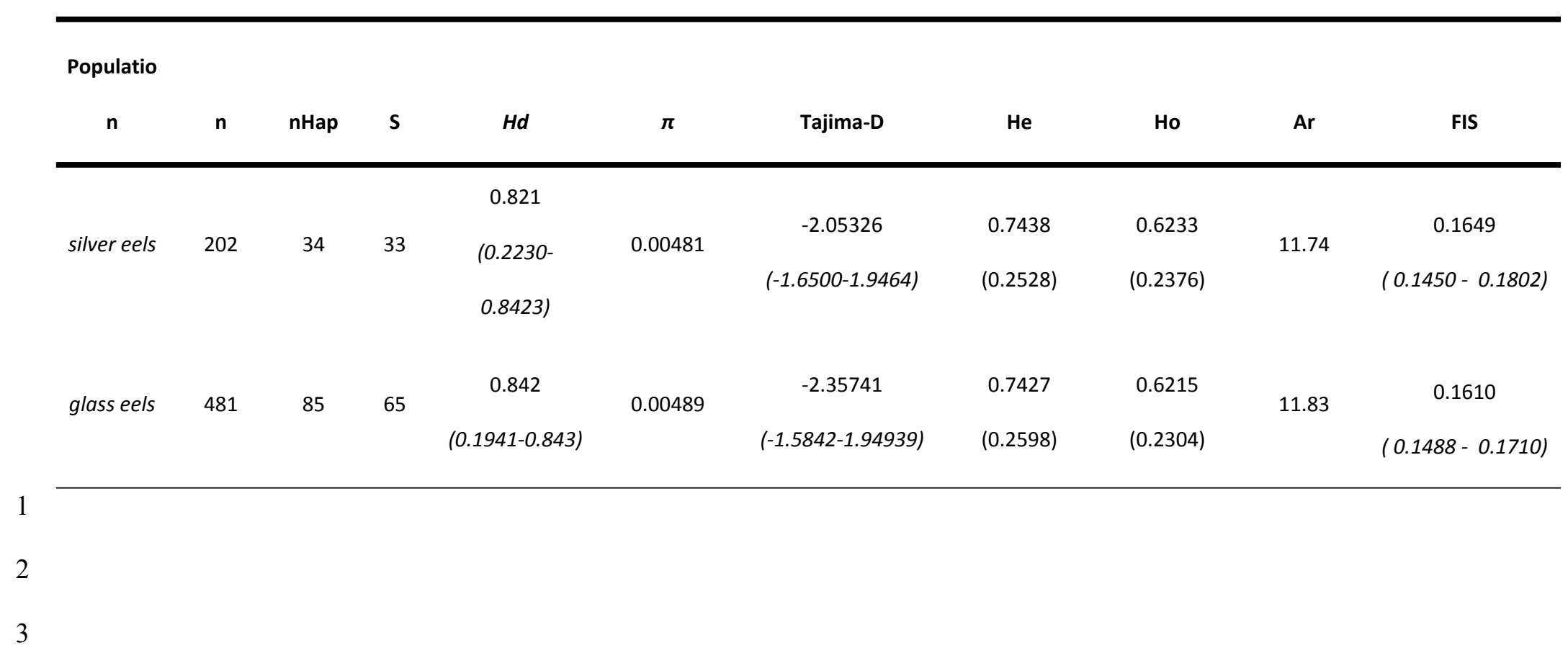




\section{Table 3 (on next page)}

MHC molecular indices for "silver eels" and "glass eels"

Summary statistics of the MHC calculated for the two distinct generations. $\mathrm{nHap}=$ number of haplotypes; $\mathrm{S}=$ segregation sites; $\mathrm{Hd}=$ Haplotype diversity; $\pi=$ nucleotide diversity; $\mathrm{k}=$ average number of differences; $\mathrm{nr}$ alleles/ind = average number alleles per individual with respective standard error (se); dist_nt = average nucleotide distance per individual with respective standard error (se); $\mathrm{R}=$ recombination rate; $\theta=$ mutation rate; $\mathrm{Rm}=$ minimum number of recombination events detected; $\mathrm{R} / \theta=$ ratio of recombination and mutation. 


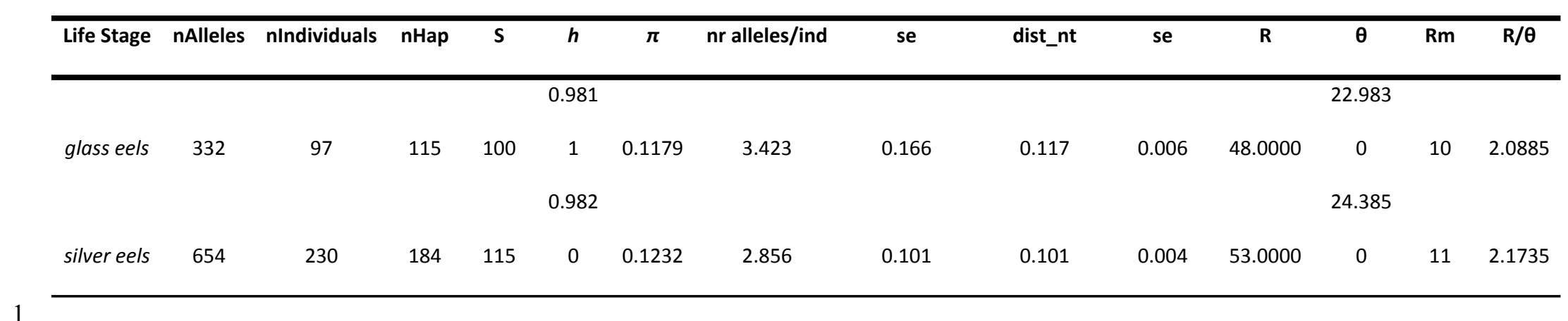




\section{Figure 1 (on next page)}

Location-specific demography accessed with neutral evolving markers

Two types of analyses specific to each marker are presented in this figure: mismatch pairwise distribution of mtDNA's single nucleotide polymorphisms within locations a) (top), and frequency distribution of allelic states across microsatellite loci b) (bot). The locations here exposed are G_AD2010 (cohort of 2010 from Adour), BU (Burrishole), SLC (LoughComber), Q (Quoile) and were chosen among the others in order to show the variety of demographic signatures produced by mtDNA data. Therefore in mismatch pairwise distribution graphs, full blue lines represent expected distribution under sudden population expansion, full red lines represent expected distribution under constant population size and dotted lines the observed distribution. The $x$-axis shows the number of mismatches and $y$ axis its frequency. It is possible to observe the signature of an expanding population in G_AD2010, stable population or recovery from bottleneck BU and SLC, and stable population in Q. Allele frequency distribution plots obtained from same locations show the signature of non-bottlenecked population b) (bot). In these graphs, the bars correspond to allele frequencies, $x$-axis corresponds to allele frequency classes and $y$-plots to number of alleles. 


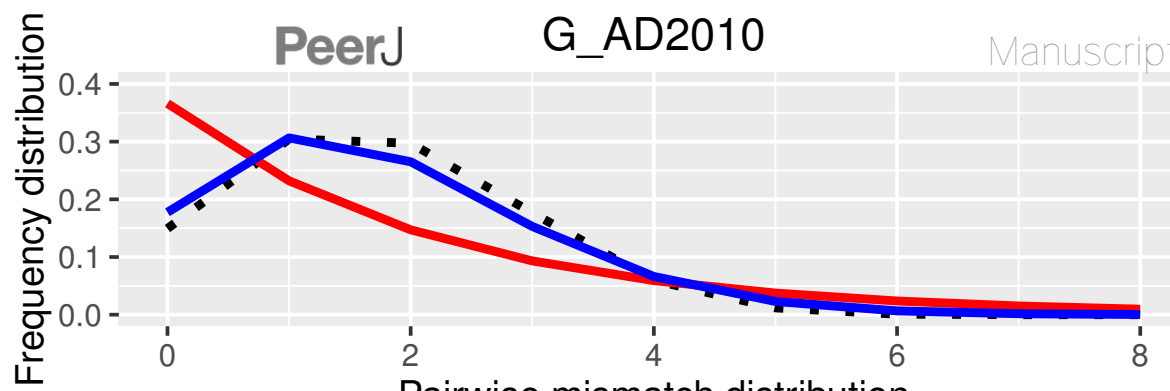

Pairwise mismatch distribution

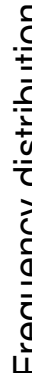

0.4 -

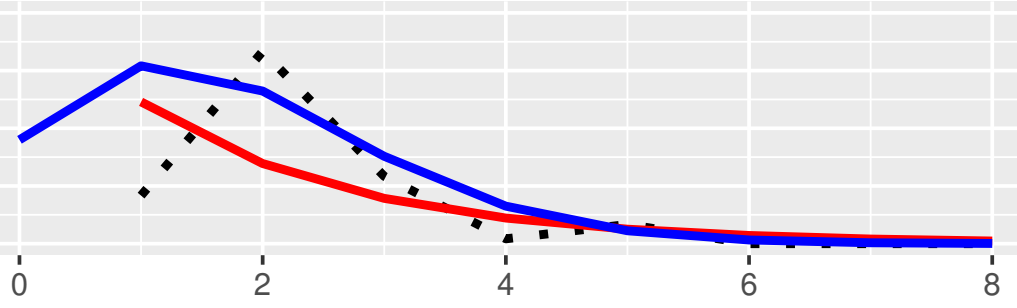

Pairwise mismatch distribution
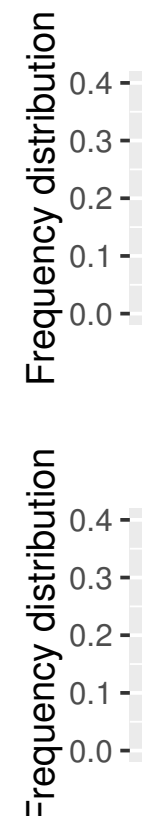

음
SLC

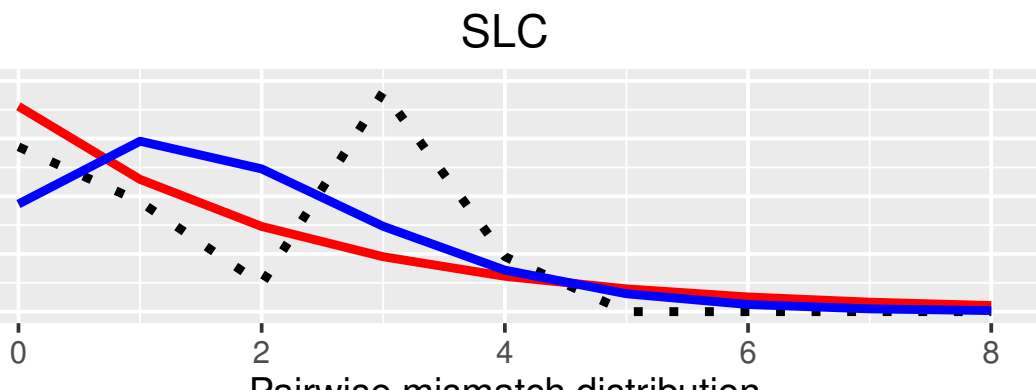

Pairwise mismatch distribution

Q

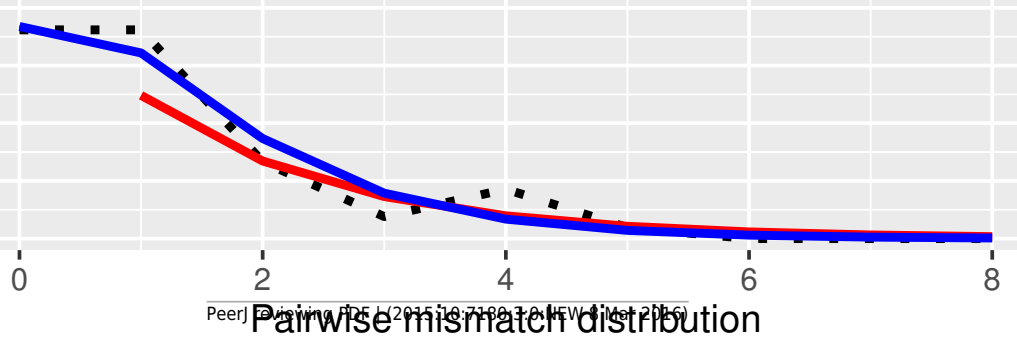

Population size changes

- observed

expected under decline

expected under expansion

Population size changes

- observed

- expected under decline

- expected under expansion

Population size changes

- observed

expected under decline

- expected under expansion

Population size changes

- observed

expected under decline

- expected under expansion 


\section{PeerJ_AD2010}

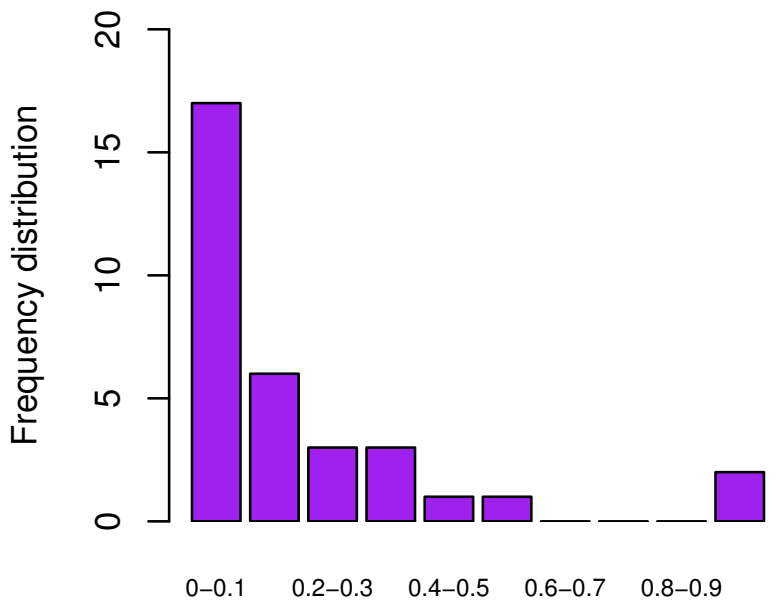

Allele frequency class

\section{SLC}

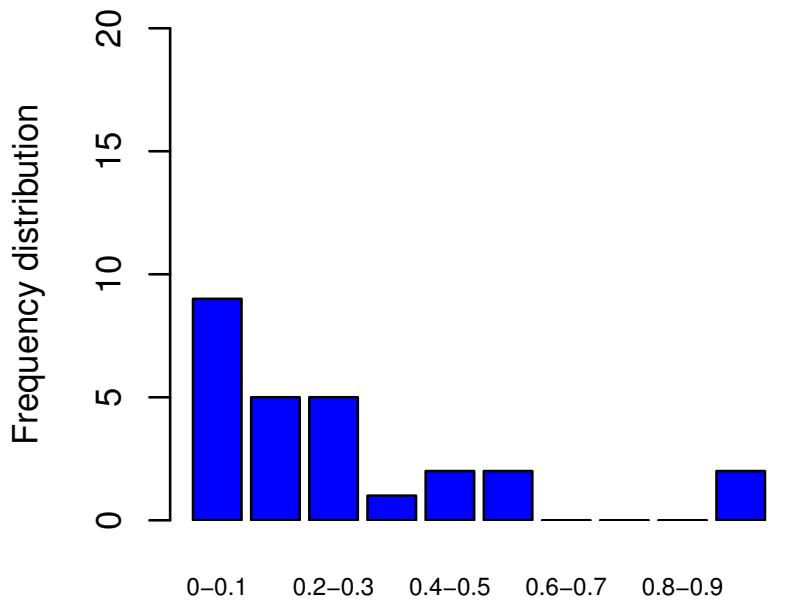

Allele frequency class

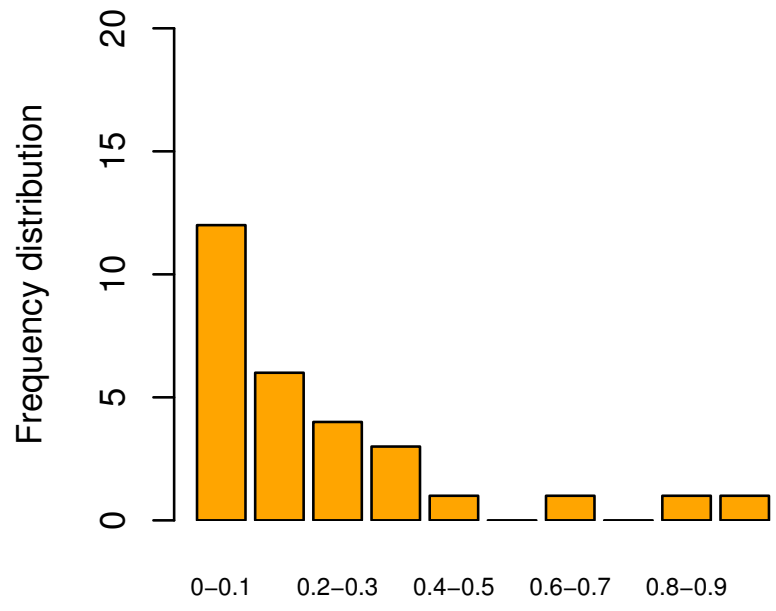

Allele frequency class

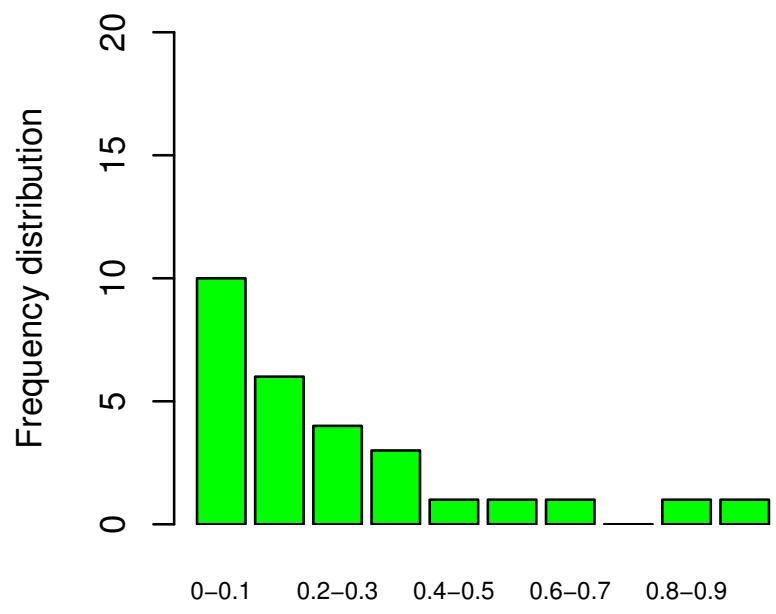

Allele frequency class 
Figure 2 (on next page)

Species and cohort-based demography accessed with neutral evolving markers

Mismatch pairwise distribution of mtDNA's single nucleotide polymorphisms considering both the full data set (top graph) and each generation separately. Here also, the full blue lines represent expected distribution under sudden population expansion, full red lines represent expected distribution under constant population size and dotted lines the observed distribution. All distributions showed a typical signature of expansion. 
Frequency фistribution of pairwise mismatches on full datasete reviewed
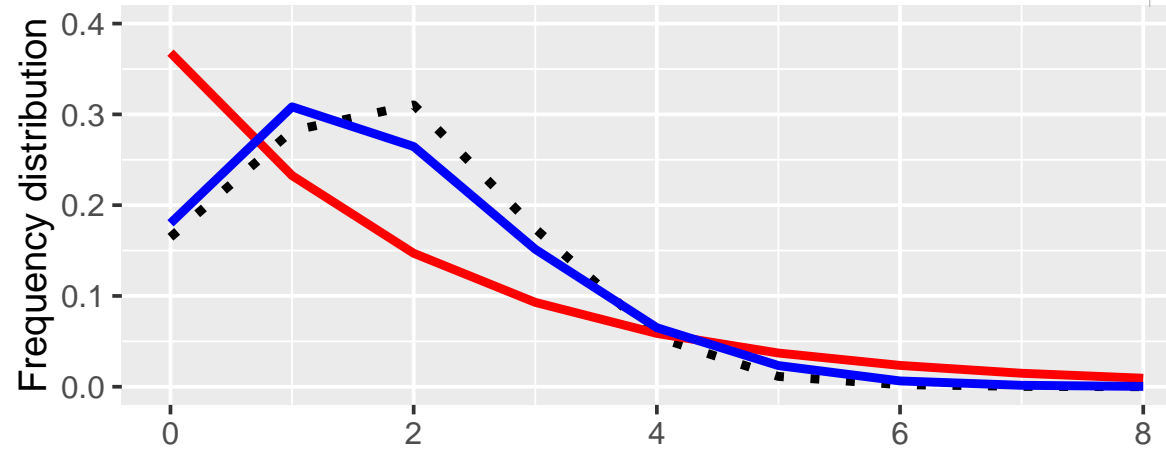

Population size changes

- observed

- expected under decline

- expected under expansion

Pairwise mismatch distribution

Frequency distribution of pairwise mismatches on silver eels

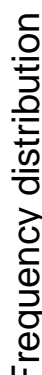
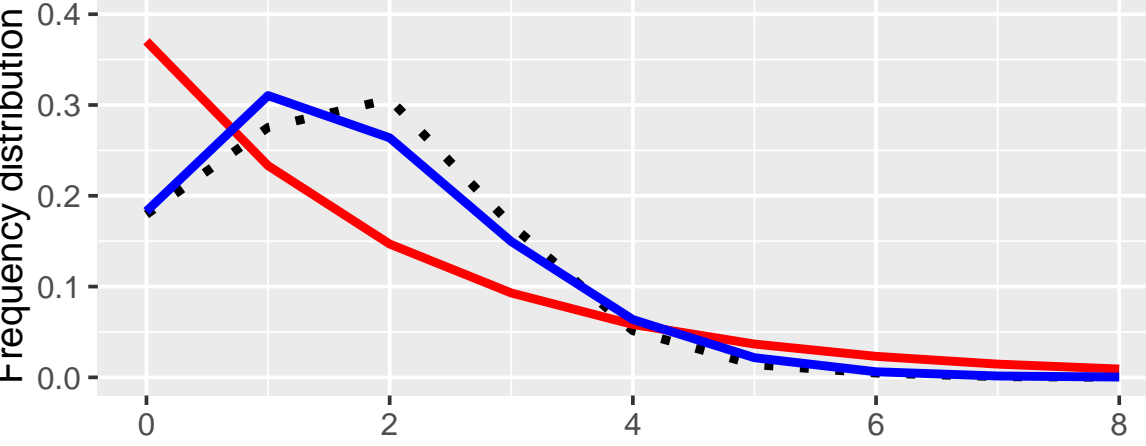

Population size changes

- observed

expected under decline

- expected under expansion

Pairwise mismatch distribution

Frequency distribution of pairwise mismatches on glass eels

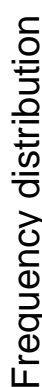
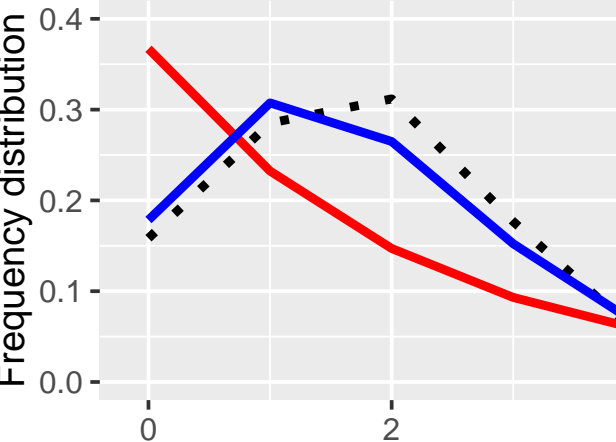

Population size changes

- observed

expected under decline

- expected under expansion 


\section{Figure 3 (on next page)}

Landmarks in the allelic sequence of exon 2 of MHC class II B of the European eel.

a) Aminoacid alignment with human HLA-DRB1. For simplification purposes, only some of the alleles are shown. + denotes human antigen binding sites, - T cell receptor contact sites and * sites that putatively interact with both. Sites estimated to be experiencing or have experienced positive selection are highlighted in green (identified by CODEML only), red (identified by MEME only) and blue (identified by both methods). b) Sliding window graph of $\psi$. Measures of the probability $(\psi)$ of a site being informative of conversion event in relation to the position in the alignment (in base pairs). Here it is possible to observe the two gene conversion tracts detected amongst "glass eels", i.e. the regions 137-141 and 166-168. 
a) PeerJ

Manuscript to be reviewed

1

22

44 66

Anan-DXBO

Anan-DXB1

QDLEFIDRYI FNKLEYARYN STLNKEIGYT EHGVKNADRW N-RDGEAERQ HANLDSYCRH NAEL--SFN

Anan-DXB2

Anan-DXB3

Anan-DXB4

Anan-DXB5

Anan-DXB6

Anan-DXB7

Anan-DXB8

Anan-DXB9

Anan-DXB10

$\ldots \ldots \ldots$. . . . . . .

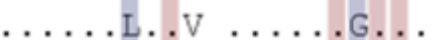

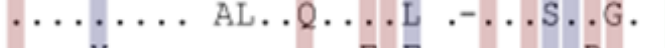

... Y.S. ...... . . . . . . . .

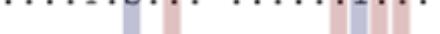

$\ldots \ldots$
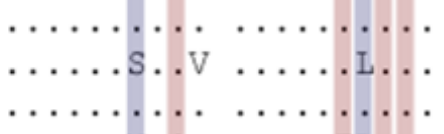

$\ldots \ldots+Q$

..Y.G. .

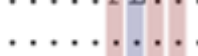

$\ldots \ldots$. . . . . .

ERVRLLE.C. Y.QE.SV.FD

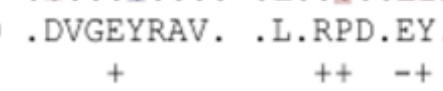

b)

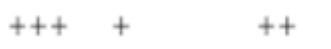

Aminoacid position

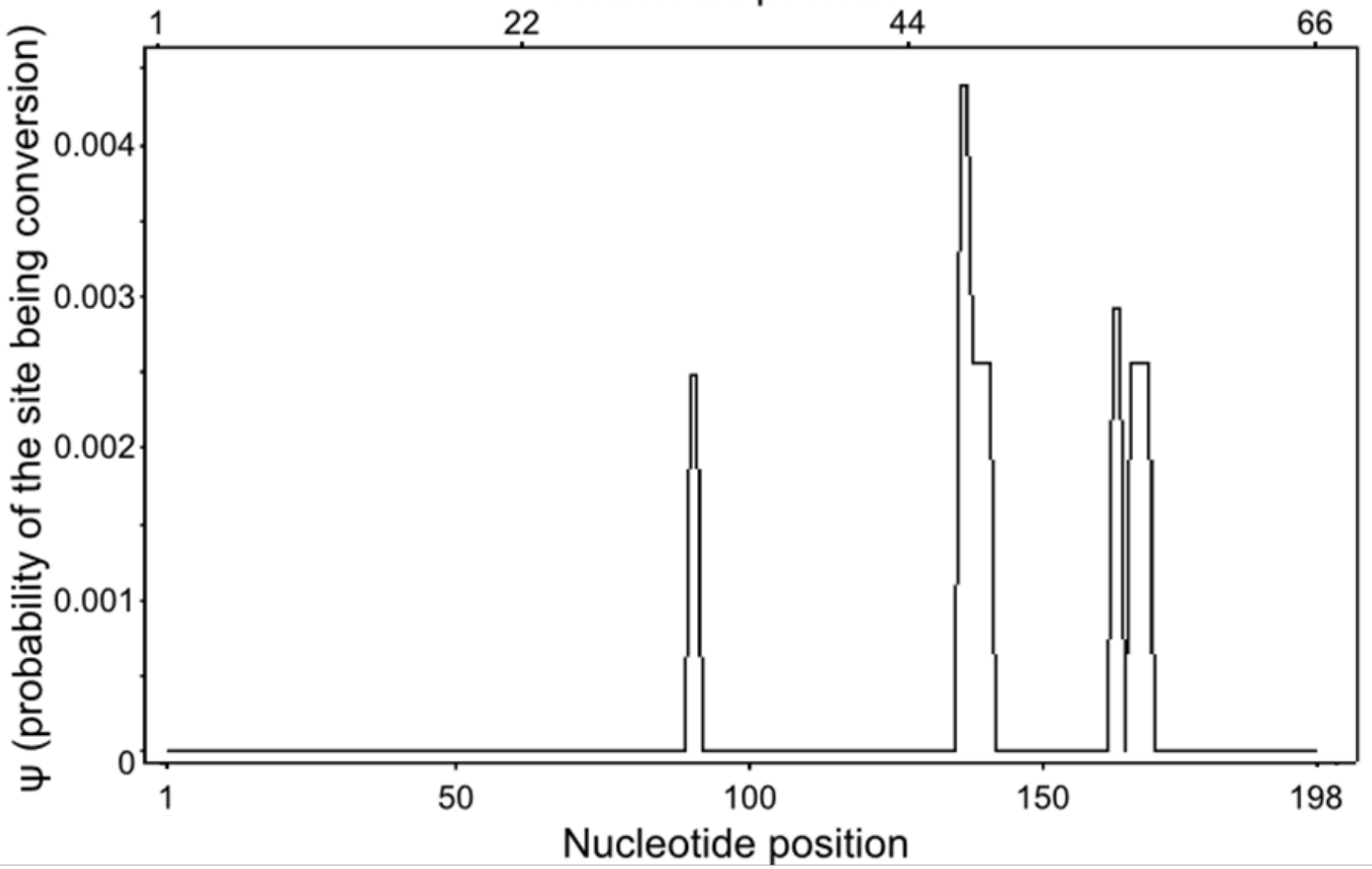




\section{Figure 4 (on next page)}

Historical profile of MHCs genetic diversity considering the positively selected sites (PSS) of the exon 2 of MHC class II B.

Above are the observed mismatch distributions of a) "glass eels" and b) "silver eels" (dotted lines) plotted against expected distribution of a population expansion (full lines). Below are the Bayesian skyline plots of "glass eels", considering 0.2 substitutions/ unit of time, c), 1 substitution/unit of time, e), and 5 substitutions/unit of time, g). On the right, Bayesian skyline plots of "silver eels", considering 0.2 substitutions/ unit of time, d), 1 substitution/unit of time, f), and 5 substitutions/unit of time, h). X-axis represents "time". The lack of a clocklike evolution did not allow the definition of a time unit. Y-axis is an estimate of the product of $\mathrm{Ne} *$ mutation rate $(\mu)$ per unit of time. The black like represents the mean $\mathrm{Ne}$ and the blue shading the $95 \%$ HPD (high probability density) interval. 
PeerJ
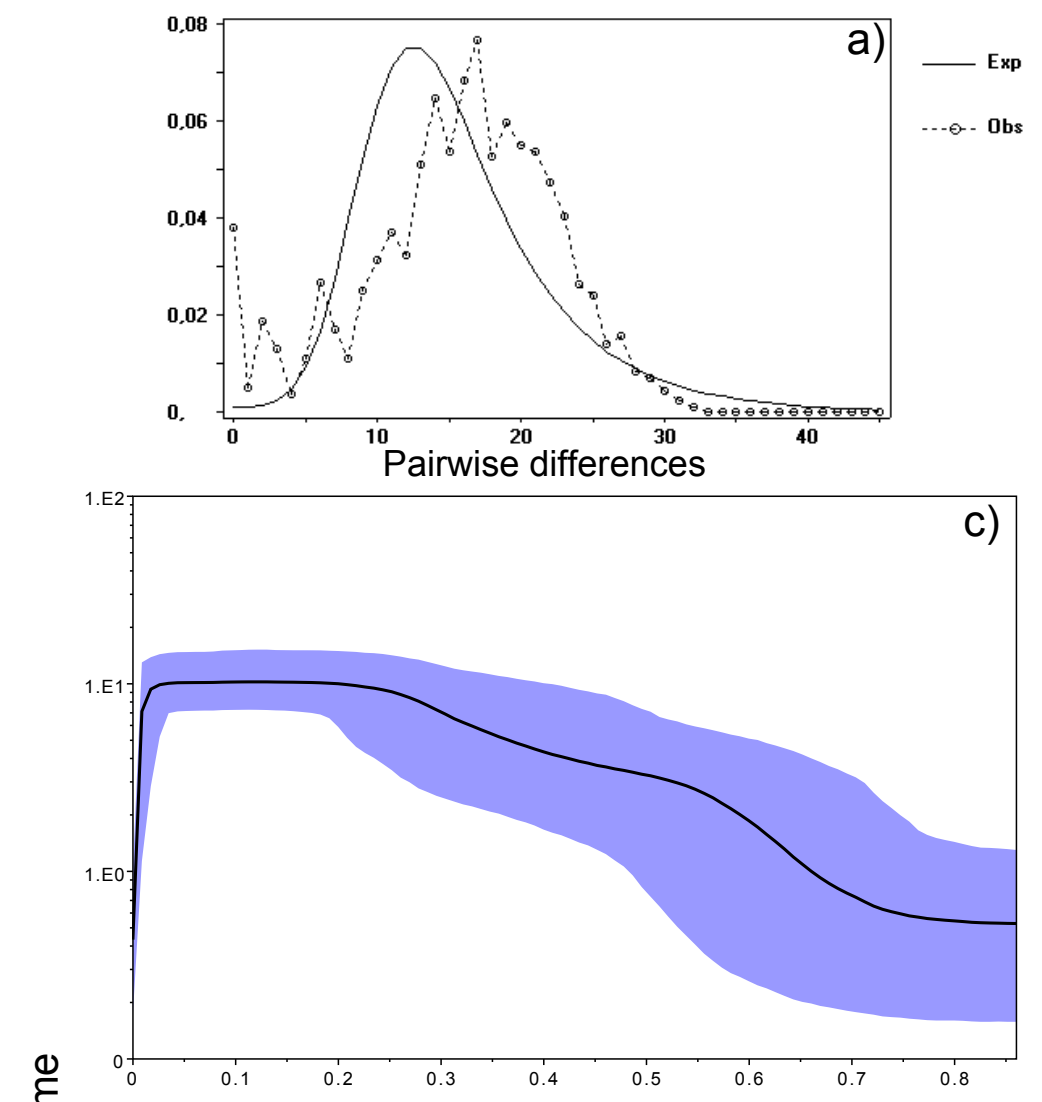

c)

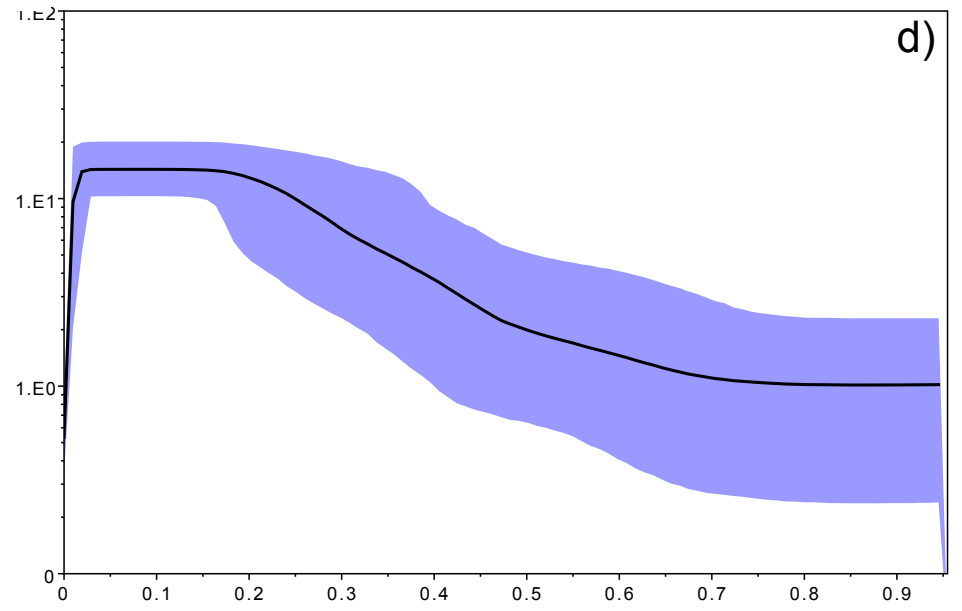

告$$
\mathrm{E}-2
$$$$
1 . \mathrm{E} 0
$$

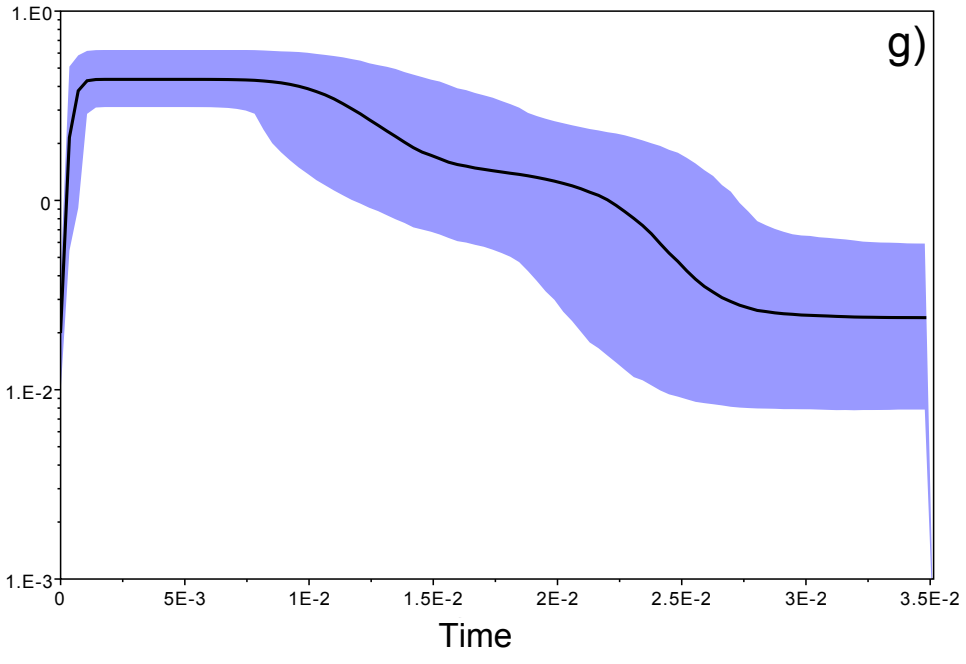

e)

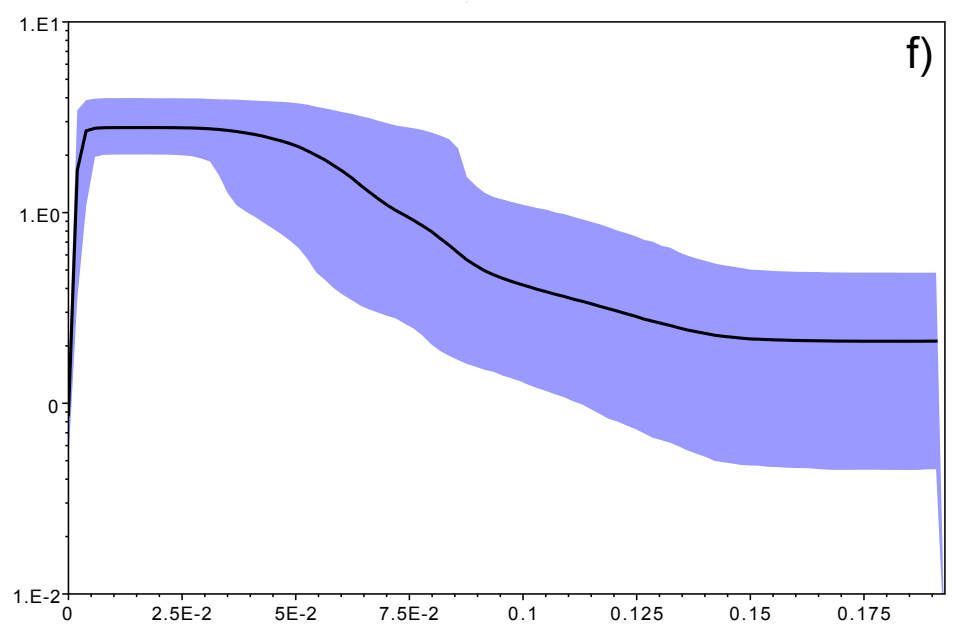

)

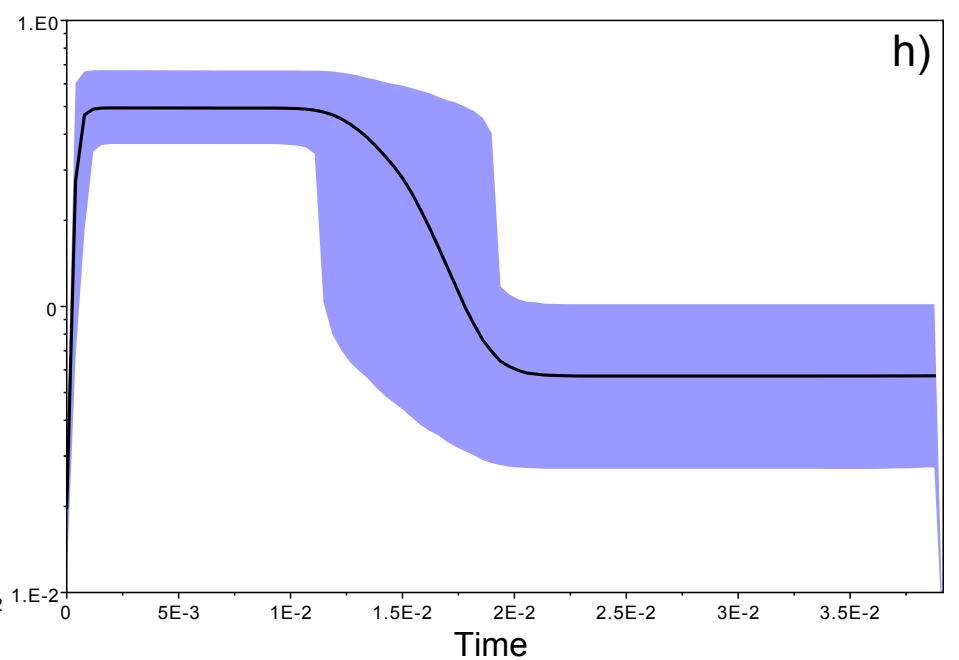


Figure $\mathbf{5}$ (on next page)

Historical profile of MHCs genetic diversity considering the non-positively selected sites (nPSS) of the exon 2 of MHC class II B

Above are the observed mismatch distributions of a) "glass eels" and b) "silver eels" (dotted lines) plotted against expected distribution of a population expansion (full lines). Below, are the Bayesian skyline plots of "glass eels", considering 0.2 substitutions/ unit of time, c), 1 substitution/unit of time, e), and 5 substitutions/unit of time, g). On the right, Bayesian skyline plots of "silver eels", considering 0.0002 substitutions/ unit of time, d), 1 substitution/unit of time, f) , and 5 substitutions/unit of time, h). 
PeerJ

Manuscript to be reviewed
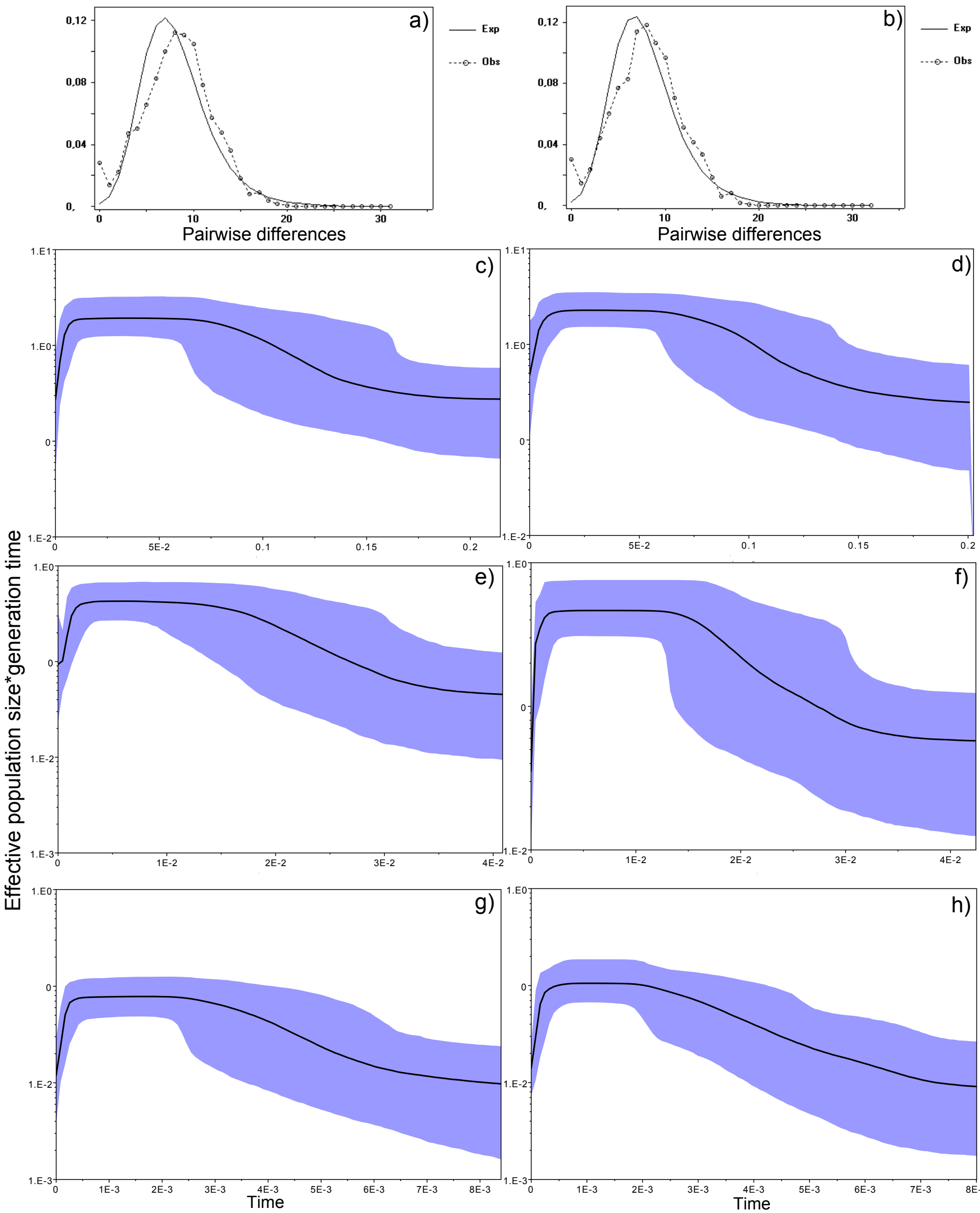

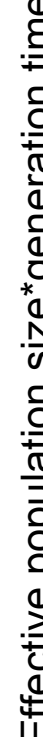
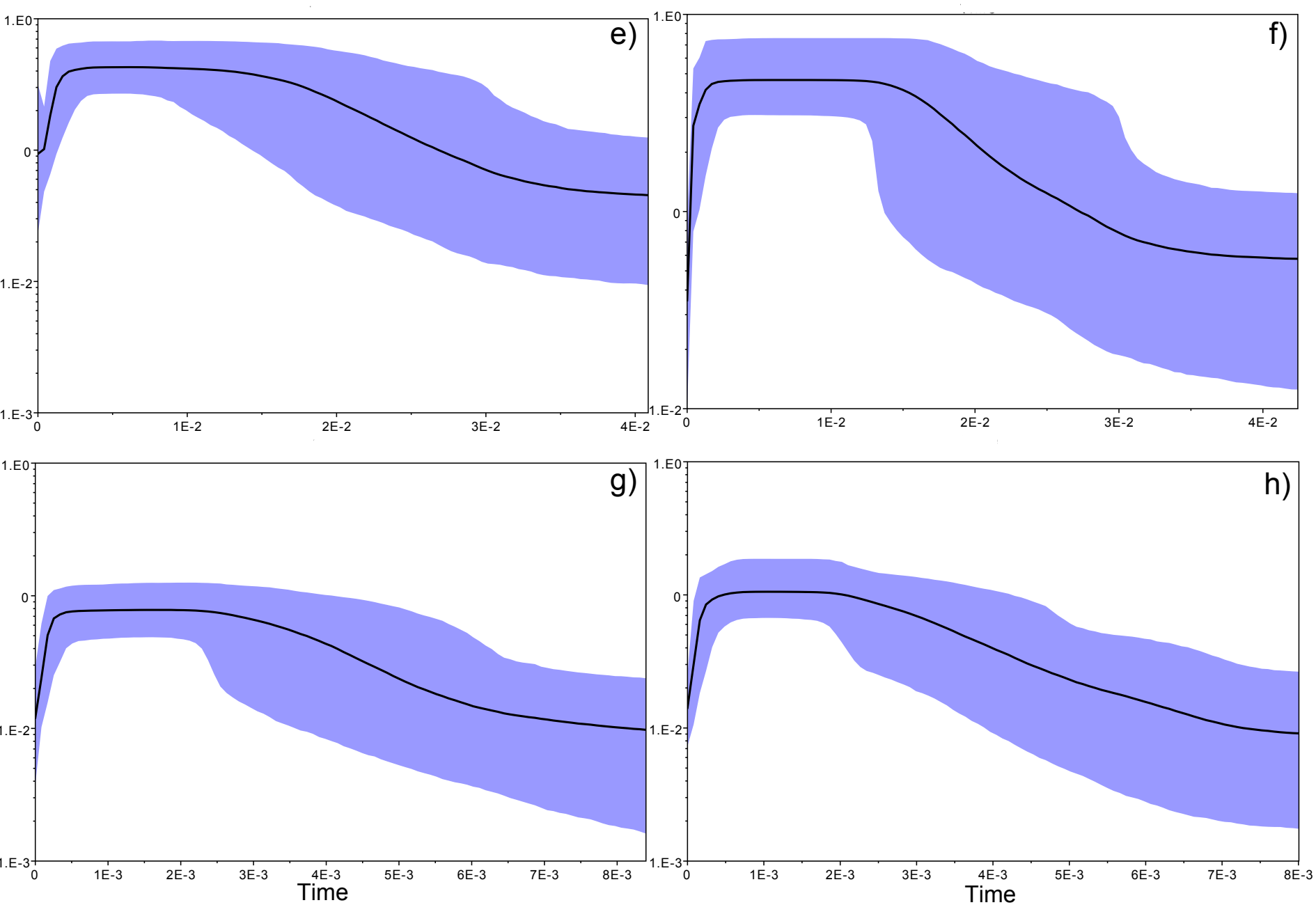
Figure $\mathbf{6}$ (on next page)

Lineages-through-time plots (LTT)

Lineage diversification for a) "silver eels" and b) "glass eels", with both graphs showing a recent burst of lineage diversification. These graphs were built with PSS using the substitution rate of 5 . Like in Bayesian skyline plots, no unit of time is defined. The y-axis represents the number of lineages through time. 


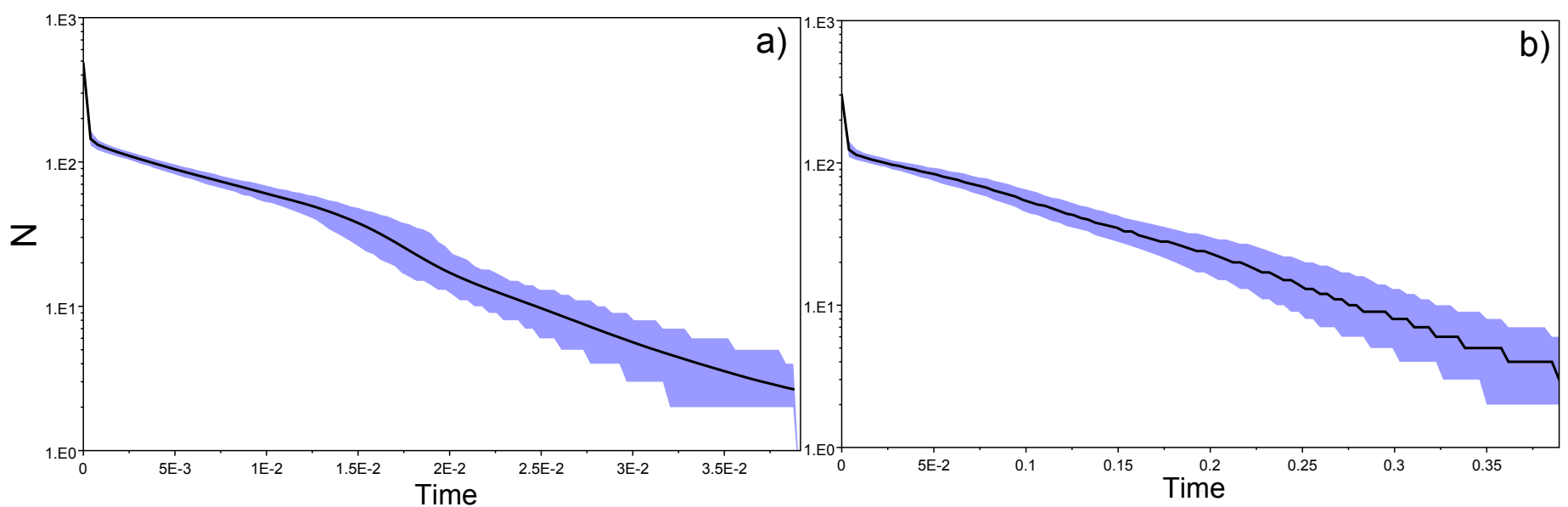

